Article

\title{
Earthen Plasters Stabilized through Sustainable Additives: An Experimental Campaign
}

\author{
Silvia Rescic ${ }^{1}$, Manuela Mattone ${ }^{2, *} \mathbb{C}$, Fabio Fratini $^{1}$ and Loredana Luvidi ${ }^{3}$ \\ 1 Florence Unit, Institute of Heritage Science (CNR-ISPC), National Research Council of Italy, \\ 50019 Florence, Italy; silvia.rescic@cnr.it (S.R.); fabio.fratini@cnr.it (F.F.) \\ 2 Department Architecture and Design, Politechnic of Turin, 10125 Torino, Italy \\ 3 Rome Unit, Institute of Heritage Science (CNR-ISPC), National Research Council of Italy, 00010 Rome, Italy; \\ loredana.luvidi@cnr.it \\ * Correspondence: manuela.mattone@polito.it
}

Citation: Rescic, S.; Mattone, M.; Fratini, F.; Luvidi, L. Earthen Plasters Stabilized through Sustainable Additives: An Experimental Campaign. Sustainability 2021, 13, 1090. https://doi.org/10.3390/ su13031090

Academic Editor: Elena Lucchi Received: 13 December 2020

Accepted: 13 January 2021

Published: 21 January 2021

Publisher's Note: MDPI stays neutral with regard to jurisdictional claims in published maps and institutional affiliations.

Copyright: (c) 2021 by the authors. Licensee MDPI, Basel, Switzerland. This article is an open access article distributed under the terms and conditions of the Creative Commons Attribution (CC BY) license (https:// creativecommons.org/licenses/by/ $4.0 /)$.

\begin{abstract}
The earthen architecture widely spread in many countries of Europe, America, Asia Africa, testifies to a particular material and immaterial culture. Nevertheless, it is a fragile heritage, which needs continuous maintenance. To encourage the preservation of such evidence of building techniques, an experimental campaign aimed at the development and evaluation of the performances of protective earthen plasters was undertaken. The durability of the plasters was improved through the addition of different additives, some of them traditional (such as lime and gypsum) and others innovative (geopolymers, enzymes), and resulting from industrial wastes (cement kiln dust). These additives have been selected considering low production costs and a reduced environmental impact, to improve the sustainability of the interventions. The performances of the earthen plasters in terms of efficacy (resistance to water erosion, water absorption, drilling, thermo-hygrometric cycles) and compatibility (changes in color and water vapor permeability) have been evaluated. Good performances were obtained by the different mixtures and, in particular, by those stabilized with gypsum. The results of this experimentation could find a useful application in the preservation of both ancient and new earthen built heritage.
\end{abstract}

Keywords: earthen plaster; stabilization; sustainability; industrial waste; geopolymer; enzymatic solution; gypsum; slaked lime

\section{Introduction}

Widespread in different climatic zones and contexts since ancient times [1,2], earthen architecture is constituted mainly by traditional rural buildings, even if many examples of monumental earthen architecture can be found (some of which entered the World Heritage List [3]). This built heritage is significant evidence of knowledge, expressions of tangible and intangible culture but, unfortunately, risks to be lost because of the gradual disappearance of the necessary maintenance practices that in the past were continuously carried out to face the aggressive action exerted by atmospheric agents [4-8].

It is widespread practice to apply a layer of plaster (sacrificial coating) on earthen constructions to guarantee their preservation. Today, as well as in the past, different types of plaster are used: earthen plasters, which are not very long-lasting and therefore needing frequent maintenance interventions; lime plasters; and sometimes also cement plasters, which are more durable, but not able to guarantee the necessary permeability to water vapor. The typical value of water vapor diffusion resistance $(\mu)$ is equal to $18-35$ for cementitious plaster, 9-11 for lime plaster, 9-10 for gypsum plaster, and 8-14 for earth plaster [4-14]. In the past few years, experimentations have been carried out to identify coatings suitable for earthen constructions [10,15-17]. The additives used to increase the durability of earthen plasters belong to two main categories, inorganic and organic (natural or synthetic) and sometimes are mixed. Among the best-known inorganic additives, lime, gypsum, Portland 
cement, materials with pozzolanic characteristics (rice husk ash, ground granulated blast, furnace slags) can be mentioned [18-21]. Lime is one of the oldest and most widely used earth stabilizers. The addition of lime improves strength, stiffness, plasticity/workability of raw earth [19-21]. Gypsum is an additive widely used for the stabilization of the earthen plasters thanks to its compatibility, breathability, elasticity, and for its low cost and eco-sustainability [21-24]. Recently, the chemical stabilization (alkaline activation or geopolymerization) was introduced for the in situ consolidation of the Alhambra earthen walls [25-27]. The organic compounds (e.g., bitumen, fibers, mucilage, gums, resin, oils and fats, starches, tannins, etc.) [28-31], traditionally used to improve the performances of earthen mortars and adobe, are numerous, very different from each other, and often mixed with the inorganic materials (e.g., lime) [32-34]. Bitumen is added in the form of an emulsion and, while drying, forms a thin film that coats the clay particles. Its main effect is the improvement of both cohesion and water resistance [33]. Fibers are widely used in earthen building. The fibers increase the tensile strength, accelerate drying, reduce both density and cracking by dispersing stresses [29,35]. The fibers most commonly adopted are straw (for example, from wheat), rice, or barley. Other suitable vegetable fibers are hay, hemp, millet, sisal, filao needles, and elephant grass. The biopolymers (e.g., mucilages, gums, resin, oils and fats, starches, tannins, etc.) are often mixed to earth too, acting in the rheology of the admixtures [36]. In some Latin American territories, particularly Mexico, earthen mixtures stabilization was traditionally carried out through the addition of vegetable fibers such as straw and mucilage of succulent plants such as the Nopal one (Opuntia Ficus Indica) $[28,33,37,38]$. More recently, synthetic compounds like PVC, polyvinyl acetate, acrylics, sodium silicate, and many others have also been introduced in various amounts as stabilizers of earthen based materials [30]. In previous experimentations, the behavior of lime and gypsum as additives, respectively at $15 \%$ and $20 \%$ by weight, was compared [24]. Gypsum resulted in being preferred as far as reduction of water absorption was concerned while lime showed better performances in terms of increasing of the plaster adherence to the support. In Mattone et al. (2017) [34], gypsum was tested together with other stabilizing additives like calcium caseinate, bitumen, vinyl resin. The resin, in combination with gypsum, improved the resistance to water erosion, decreasing the water absorption capacity and increasing the water repellence (Karsten test and contact angle), but to the detriment of the water vapor permeability. To foster the preservation of the earthen heritage, an experimental campaign was carried out aimed at identifying earthen plasters able to protect earthen constructions from the aggressive action exerted by natural agents. To promote sustainable intervention with products characterised by low production costs and reduced environmental impacts, additives such as gypsum, slaked lime, geopolymeric solution, enzymatic solution, and waste from cement production (cement kiln dust-CKD), were selected [35]. Except for gypsum, whose action is to fix without interacting with the earth (in particular the clay fraction), the other materials interact in various ways with the clay fraction both modifying the rheological characteristics (enzymes) and reacting, giving rise to new compounds (slaked lime, geopolymeric solution, CKD), as will be explained later (see paragraph 2.1 Materials). As regards to the amount of additive to be used in the mixture, we started from $5 \%$ by weight of lime $[19,39]$ and then the other additives (CKD and gypsum) were added in powder in the same percentage. For the additives in solution (geopolymers and enzymes), reference was made to previous works $[40,41]$ or to what was suggested by the technical sheet (enzymatic solution). The gypsum was deliberately tested also at $20 \%$ because of the good results obtained in previous experimental activities [24]. Analyses have been carried out to characterize the raw materials (grain size distribution, mineralogical, and chemical composition) and the modifications induced in the clay minerals by those additives capable to react with them.

The performances of earthen plasters have been evaluated in terms of efficacy and compatibility. Water erosion resistance (Geelong test and erosion spray test as provided by New Zealand standards NZS 4298-1998 E-D) [42,43], superficial mechanical cohesion (drilling 
resistance test), water absorption [44,45], durability (resistance to thermo-hygrometric cycles), water vapor permeability [46], and colour change have been tested [47].

\section{Materials and Methods}

\subsection{Materials}

Plaster specimens were prepared by using earthen material taken from Santena (Turin, Piedmont, Italy) where a clayey soil is widely available and adopted in the past for the construction of vernacular buildings (see Appendix part A in Supplementary Materials). The gypsum used in this experiment is a commercial one usually identified with the Italian name "scagliola" but commonly known as plaster of Paris and consists of white powder of calcium sulfate hemihydrate: $\mathrm{CaSO}_{4} \cdot 0.5 \mathrm{H}_{2} \mathrm{O}$ (bassanite). Gypsum has been employed as a soil stabilizer that creates a crystalline network with clays that add rigidity $[6,23,24,34,48,49]$. Furthermore, during the setting phase, it increases in the volume of about $0.5 \%$ [50], contrasting earthen shrinkage during the drying phase. Regarding the amount of gypsum to be added to the mixture, previous research conducted by the authors [23] showed that good results can be achieved adding $20 \%$ of gypsum. For this reason, it was decided to test mixtures adding both $5 \%$ and $20 \%$ by weight of gypsum, to verify if even a smaller quantity (comparable with the additions of slaked lime and CKD) would give satisfactory results (see Table 1).

Lime. As far as lime is concerned, several authors have studied its interaction with the earth and it has been observed that the addition of lime improves strength, stiffness, plasticity/workability of raw earth [51]. The $\mathrm{pH}$ of lime in water, normally above 12.4 (the $\mathrm{pH}$ of a saturated solution of lime-water) favors the solubilization of silica and alumina present in the clay minerals that react with the $\mathrm{Ca}++$ ions to form silico-calcium aluminates with cementing action compacting the plaster mixture [20]. The slaked lime used in this experiment is a lime aged 48 months, produced by Viva Lime (Fasano, Brindisi-Italy).

Geopolymeric solution. A geopolymer is an inorganic binder with an alumino-silicate composition formed through a process of polymerization by condensation of silica and alumina tetrahedrons [52]. The geopolymeric solution is highly alkaline (the $\mathrm{pH}$ is typically around 11-12) and therefore it can attack the crystal lattice of the clay minerals characterized by weak links between the elementary packets, namely the smectites [53]. These minerals release silicon and aluminum that by condensation form silico-aluminates compounds with cementing action (calcium silicate hydrate, calcium aluminate hydrate, and/or zeolite-like phases) [25-27].

Four days before use, the geopolymeric solution was prepared by mixing potassium silicate ( $38 \%$ by weight, marketed in liquid form by Ingessil SRL-Montorio-Verona, Italy) with potassium hydroxide ( $\mathrm{KOH} 1.0 \mathrm{M}$, chemical grade by Sigma Aldrich), to obtain a solution with a mass ratio between silicate and potassium hydroxide equal to 1.0 [39]. The type of alkaline activator and the ratio $\mathrm{K}_{2} \mathrm{SiO}_{3} / \mathrm{KOH}$ was selected based on the best compressive strength obtained by Hardjito and Fung [41].

Enzymatic solution. The enzymatic solution, used as a soil stabilizer, usually, is obtained by the fermentation of plant extracts by microorganisms. Unfortunately, the supplier does not provide the composition and, therefore, it is very difficult to determine the stabilization mechanism of soil [54]. A possible action mechanism proposed by Scholen, [55] and confirmed by other authors [56], hypothesizes firstly, that enzymes bind with large organic molecules present in the soil; secondarily, the enzymes linked with the organic molecules surround the clay minerals, preventing the absorption of moisture and subsequent swelling. Besides, the modification of the surface charge of clay minerals favors compaction [54]. It must be considered that enzymes are biological catalysts of specific reactions and these reactions depend on various factors such as $\mathrm{pH}$, temperature, the presence of organic matter in the soil, and other factors that directly influence chemical reactions in the soil. Furthermore, the catalysts remain unaffected at the end of the reaction but are degradable materials so that they can break down and dissolve over time. 
TerraZyme is an enzymatic solution obtained by the fermentation of plant extracts by microorganisms (TerraZyme ${ }^{\circledR}$ soil stabilizer is manufactured in the United States by Nature addition, Inc.). Unfortunately, no information about the composition is provided by the supplier [57]. The product works well in the stabilization of soils with 10-15\% by weight of clay minerals. Based on the indications of the supplier, the solution was diluted with distilled water to $5 \%$ by weight of the product.

Cement kiln dust. CKD [58-60] is a waste of the cement industry consisting mainly of calcium carbonate and silicon dioxide, with various per cent of alkali, chlorides, and sulfates. It works similarly to lime: in presence of water, calcium oxide, and hydroxide, in combination with other alkaline compounds, it raises the $\mathrm{pH}$ of the mixture above 12, fostering the development of cementing compound. The CKD used in this work comes from the Heidelberg Cement Plant (Heidelberg, Germany).

\subsection{Samples Composition, Preparation, and Characteristics}

Table 1 shows the detailed composition of the different plasters tested. The additives percentages refer to the weight of the dry earthen materials.

Table 1. Sample composition of the earthen plaster mixtures.

\begin{tabular}{cccc}
\hline Samples ID & Additive & $\begin{array}{c}\text { \% by Weight of } \\
\text { Additive }\end{array}$ & $\begin{array}{c}\text { \% by Weight of } \\
\text { Water }\end{array}$ \\
\hline Earth & Not present & - & 28 \\
\hline A & Slaked lime & 5 & 28 \\
\hline B & $\begin{array}{c}\text { Geopolymeric } \\
\text { solution }\end{array}$ & 40 & $* *$ \\
\hline C & Enzymatic solution & 30.5 & 36 \\
\hline D & CKD & 5 & 28 \\
\hline E & Plaster of Paris & 20 & 28 \\
\hline F & Plaster of Paris & 5 & \\
\hline${ }^{*}$ respect to the weight of the dry earthen material; ${ }^{* *}$ no water was added because the additive is in the \\
aqueous phase.
\end{tabular}

All the earth + additives mixtures were realized with a mixer to ensure good homogenization between earth and additives. Samples were prepared by providing the first layer of plaster (thickness $1.5 \mathrm{~cm}$ ) using earthen material with coarser particle size (passing through a $\varnothing 2 \mathrm{~mm}$ mesh sieve), coated with a finishing layer (thickness $0.5 \mathrm{~cm}$ ) prepared with an earthen material of finer granulometry (passing through a $\varnothing 1 \mathrm{~mm}$ mesh sieve). Before testing, the plasters were left for about 45 days under room conditions $\left(\mathrm{T}=23{ }^{\circ} \mathrm{C}\right.$, $\mathrm{RH}=50 \%$ ) in order curing. The same curing condition ( $\mathrm{T}$ and $\mathrm{RH}$ ) has been adopted after this time. The plaster samples stabilized with slaked lime, CKD, and geopolymeric solution, during the first month, have been sprinkled one time daily (about $0.11 / \mathrm{m}^{2}$ ), at the same time, with deionized water to favor the formation of the new compounds. Then, they have been left drying up to constant weigh, reached after 15-20 days under the previous conditions (i.e., $\mathrm{T}=23{ }^{\circ} \mathrm{C}, \mathrm{RH}=50 \%$ ). In the case of the earthen plaster $+\mathrm{CKD}$, after 45 days of curing, the formation of a whitish powder on the surface was noted which was delicately removed with a soft brush. This powder was found to be essentially constituted by sylvite $(\mathrm{KCl})$ and arcanite $\left(\mathrm{K}_{2} \mathrm{SO}_{4}\right)$. In the following year, this efflorescence no longer formed. However, this drawback has cast doubts on the feasibility of using CKD as an additive.

Four samples of earthen plaster, $25 \times 25 \times 2 \mathrm{~cm}$ (each one composed of two layers, as described above), were made for each type of plaster mixture. One of these samples was cut in 12 specimens $5 \times 5 \times 2 \mathrm{~cm}$ to perform colorimetric measurements, drilling resistance tests, water vapor permeability tests, and thermo-hygrometric cycles. The other three $25 \times 25 \times 2 \mathrm{~cm}$ samples were used for water erosion and water absorption tests. As 
for the water vapor permeability, special samples $5 \times 5 \times 2 \mathrm{~cm}$ were realized, made only of one single layer. In fact, according to the European standard EN 15803 [46], this kind of test must be carried out on non-stratified samples. Therefore, we decided to test both the non-stratified and stratified samples. Table 2 summarizes both the dimension and the number of the specimens and the type and the number of tests that have been carried out.

Table 2. Scheme of the experimental tests

\begin{tabular}{|c|c|c|c|c|}
\hline Test & $\begin{array}{l}\text { Sample Size } \\
\text { (cm) }\end{array}$ & $\begin{array}{l}\text { Samples for } \\
\text { Each Plaster } \\
\text { Mix }\end{array}$ & $\begin{array}{l}\text { Tests for Each } \\
\text { Sample }\end{array}$ & $\begin{array}{l}\text { Total Number } \\
\text { of Test for Each } \\
\text { Plaster Mix }\end{array}$ \\
\hline Water spray erosion & $25 \times 25 \times 2$ & 3 & 1 & 3 \\
\hline $\begin{array}{c}\text { Water Geelong } \\
\text { erosion }\end{array}$ & $25 \times 25 \times 2$ & 3 & 3 & 9 \\
\hline Water absorption & $25 \times 25 \times 2$ & 3 & 3 & 9 \\
\hline Color $\S$ & $5 \times 5 \times 2$ & 9 & 3 & 27 \\
\hline $\begin{array}{c}\text { Water vapor } \\
\text { permeability } \\
\text { (two layers sample) }\end{array}$ & $5 \times 5 \times 2$ & 3 & 1 & 3 \\
\hline $\begin{array}{l}\text { Water vapor } \\
\text { permeability } \\
\text { (one-layer sample: } \\
\text { fine earth fraction } \\
\varnothing<1 \mathrm{~mm} \text { ) }\end{array}$ & $5 \times 5 \times 2$ & 3 & 1 & 3 \\
\hline $\begin{array}{c}\text { Water vapor } \\
\text { permeability } \\
\text { (one-layer sample: } \\
\text { coarse earth fraction } \\
1 \mathrm{~mm}<\varnothing<2 \mathrm{~mm} \text { ) }\end{array}$ & $5 \times 5 \times 2$ & 3 & 1 & 3 \\
\hline Drilling resistance & $5 \times 5 \times 2$ & 3 & 3 & 9 \\
\hline $\begin{array}{c}\text { Thermo-hygrometric } \\
\text { cycles }\end{array}$ & $5 \times 5 \times 2$ & 3 & 1 & 3 \\
\hline
\end{tabular}

\subsection{Analytical Methods}

\subsubsection{Characterization of Raw Materials}

The grain size distribution of the earthen material was determined according to the standard practice ASTM D2217-85 [61] and ASTM D422-63 [62]: the grain size distribution of particles larger than $75 \mu \mathrm{m}$ was determined by sieving, while the distribution of particles smaller than $75 \mu \mathrm{m}$ was determined through sedimentation. As for gypsum, slaked lime, and CKD, the fraction $<4 \mu \mathrm{m}$ has been adopted.

The mineralogical composition of the whole earthen materials (sand + silt + clay) and additives were determined through X-ray diffraction with an X'Pert PRO diffractometer by PANalytical equipped with $X^{\prime}$ Celerator detector and HighScore software for acquisition and interpretation of the data according to the following operative conditions: $\mathrm{Cu} \mathrm{K} \alpha 1 \lambda=1.545 \AA, 40 \mathrm{kV}, 30 \mathrm{~mA}, 2 \theta=3-70^{\circ}$.

The analysis of the clay minerals fraction has been performed according to Cipriani's methodology [63] adopting a PHILIPS PW 1729 diffractometer (operative conditions: $\mathrm{Cu}$ $\mathrm{K} \alpha 1 \lambda=1.545 \AA, 40 \mathrm{kV}, 20 \mathrm{~mA}, 2 \theta=3-20^{\circ}$ ). The fraction $<4 \mathrm{~mm}$, mainly constituted by clay minerals, has been separated. This fraction was placed on a small sheet of glass where it dried and formed an oriented powder sample. To recognize the different clay minerals, the oriented powder samples (not treated; treated with ethylene glycol; heated at $450{ }^{\circ} \mathrm{C}$ ) have undergone XRD scanning. The treatments (ethylene glycol and heating at $450{ }^{\circ} \mathrm{C}$ ) cause the shifting or the disappearance of the basal reflections of some clay minerals and allow their identification. 
The chemical composition of CKD was determined by X-ray fluorescence (XRF) on pressed powder pellets, using a Philips PW 1480 wavelength-dispersive spectrometer; major and minor elements were determined using a Rh anode and corrected for the matrix effect according to the method of Franzini et al. [64]. Accuracy and precision were checked using international reference samples (e.g., NIM-G, G2, W2, GS-N, GH, W1, GA, AC-E, etc.). An error has been evaluated to be less than $1 \%$ for the major elements and $5 \%$ for the minor elements.

LOI (loss on ignition) was determined by measuring the mass loss in the sample powders heated at $950{ }^{\circ} \mathrm{C}$ for $1 \mathrm{~h}$. The XRF compositional results were expressed as oxide weight ( $\mathrm{wt} \%$ ) normalized to $100 \%$.

\subsubsection{Mineralogical Modification in Clay Fraction Reacting with Additives}

The influence of the additive's interaction see (Appendix part B in Supplementary Materials) with the clay fraction (slaked lime, geopolymeric solution, CKD) was studied by examining the X-ray diffraction performed on the oriented powder clay fraction (only on the not-glycolated and not-heated powder), respectively after 45 days and one year (cured at the same room conditions i.e., $23{ }^{\circ} \mathrm{C}$ and $50 \% \mathrm{UR}$ ), according to the methodology previous described [63].

To support the XRD data, a thermogravimetric analysis (TGA) was carried out on the clay fraction extracted after one year. A Pyris 6 TGA by Perkin Elmer, equipped with Pyris TGA software for acquisition and elaboration of the data, was used. A small amount of the sample (3-4 mg) was placed in a ceramic crucible under $\mathrm{N} 2$ gas atmosphere with a flow rate of $20 \mathrm{~mL} / \mathrm{min}$ and analyzed from $50^{\circ} \mathrm{C}$ up to $800{ }^{\circ} \mathrm{C}$ at a rate of $10^{\circ} \mathrm{C} / \mathrm{min}$.

\subsubsection{Effect of the Additives in Term of Earthen Plaster Performances}

The water erosion resistance was evaluated according to New Zealand NZS 4298 D-E standards [43,44], in two different ways: Geelong test and spray test. The first test determines the erodibility of the earthen material in areas where annual precipitation is around $500 \mathrm{~mm}$. The second one simulates two conditions of erosion of earthen surfaces due to rainfall: humidification and kinetic energy impinging on earthen material. These latter conditions are more severe than those of the Geelong test [65].

Geelong Test. The Geelong test is based on the measurement of the sample's erosion caused by the repeated impact of a water drop-from a height of $400 \mathrm{~mm}$ and for a total of $100 \mathrm{~mL}$ - on the tested surface, placed at an angle of nearly $30^{\circ}$ to the horizontal (Figure 1). Erosion is evaluated by measuring the depth of the cavity caused by the impact of the water drop on the surface. According to NZS 4298-E [44], Standards Association of Zimbabwe [66] and Standards Australia [67], failure of the specimen occurs when the pitting depth is greater than $15 \mathrm{~mm}$.

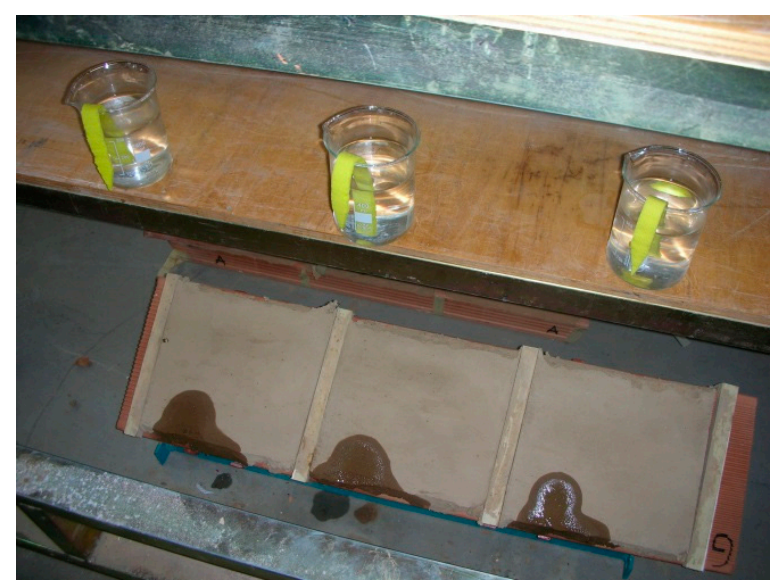

Figure 1. Geelong test. 
Spray Erosion Test. The spray erosion test involves the measurement of the erosion of the sample due to its exposition to a water jet projected from a distance of $470 \mathrm{~mm}$ and with a pressure of 0.5 bar. The test lasts up to one hour, or until complete erosion of the sample and it is interrupted at regular intervals of $15 \mathrm{~min}$ to evaluate the depth of the erosion caused by water jet. According to NZS 4298 -D [43] and SAZS 724 [65], failure of the specimen occurs when the depth of erosion is greater than $20 \mathrm{~mm}$ (Figure 2).

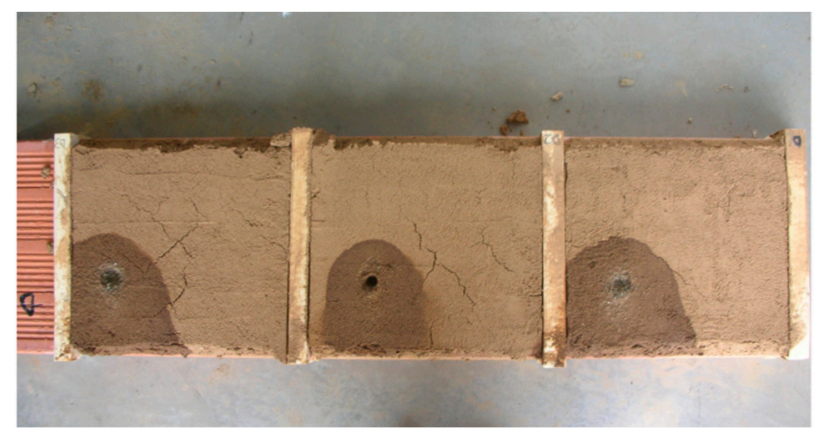

Figure 2. Spray erosion test.

Changes in the superficial mechanical cohesion due to the additives were assessed by measuring the drilling resistance with the drilling resistance measurement system (DRMS by Sint Technology, Italy) [68-70]. The following operating conditions were adopted: $200 \mathrm{rpm}$ speed of rotation of the bit, $10 \mathrm{~mm} / \mathrm{min}$ forward speed of the bit, $10 \mathrm{~mm}$ depth of the hole. A Fisher carbide-tipped masonry drill bit (for cement and stones) with a diameter of $5 \mathrm{~mm}$ was used. Nine measures for each type of earthen plaster have been carried out. All the plaster B specimens (geopolymer) broke at the beginning of the test, during the closure of the sample holder.

The water absorption tests were performed through a Karsten pipe [44,45], a pipeshape graduated device. Having fixed the pipe to the vertical surface with silicone and filled it with water, a decreasing water column was applied on a circular surface of $5.7 \mathrm{~cm}^{2}$. The drop in the water level was measured at constant intervals of time (one minute), for a maximum of $15 \mathrm{~min}$. The results of the measures were reported on a graph and the rate of water absorption in units of time was evaluated.

The water vapor permeability is an important parameter concerning the compatibility. Changes in water vapor transport properties may cause water condensation and its accumulation at the interface between the different plaster layers and the wall, causing decay phenomena such as detachment [71]. The water vapor permeability test was conducted according to the procedure and instrumentation described in the European standard EN 15803 [46], measuring the mass of vapor flowing every $24 \mathrm{~h}$ up to 10 days when equilibrium was reached. The test chamber was maintained at a constant temperature of $23{ }^{\circ} \mathrm{C}$ and relative humidity of $50 \%$. The test result is reported as $\mu$ (water vapor diffusion resistance coefficient) [46]. Currently, in the EN 15803: 2010 standard, there are no indications for an acceptable range of water vapor permeability variation. In Snethlage [72], a maximum variation threshold of $20 \%$ is proposed while according to Delgado and Grossi [73], this threshold is lower $(10 \%)$. A prudent approach, in evaluating this parameter, suggests that the threshold proposed by Delgado and Grossi [73] should be considered as the most suitable in the interpretation of the results. The percentage of variation referred to the parameter $\mu$ is calculated as follows:

$\Delta \mu(\%)=(\mid \mu \text { plaster of only earth }-\mu \text { plaster with additive } \mid / \mu \text { plaster of only earth })^{*} 100$.

Color changes due to the addition of the additive to the earthen plaster are a purely aesthetic parameter that concerns the compatibility and it becomes very important in the case of integration of missing plasters. A Konica Minolta spectrophotometer CM 700d, adopting the CIE L* $\mathrm{a}^{*} \mathrm{~b}^{*}$ method [74], was employed to measure the color parameters. The 
color of a surface is described by three parameters: $L^{*}(0$ to 100$)$ represents the lightness, $a^{*}$ is related to the impulse of red-green color, and $b^{*}$ is related to the impulse of the yellowblue color [47]. The total change of color is summarized by the parameter $\Delta \mathrm{E}^{*}$ calculated with the following equation:

$$
\Delta \mathrm{E}^{*}=\left[\left(\Delta \mathrm{L}^{*}\right)^{2}+\left(\Delta \mathrm{a}^{*}\right)^{2}+\left(\Delta \mathrm{b}^{*}\right)^{2}\right]^{1 / 2}
$$

where $\Delta \mathrm{L}^{*}=$ ( $\mathrm{L}^{*}$ plaster with additive-L*plaster of only earth); $\Delta \mathrm{a}^{*}=$ (a* plaster with additive$a^{*}$ plaster of only earth); $\Delta b^{*}=\left(b^{*}\right.$ plaster with additive- $b^{*}$ plaster of only earth).

The measurements were performed with diffuse illumination (D65 standard source) on an area of $8 \mathrm{~mm}$ in diameter, with a specular component included and excluded. Three measurements for each sample were carried out ( 9 samples for each plaster).

Accelerated ageing such as wet-dry $[75,76]$, freeze-thaw $[77,78]$ and thermo-hygrometric cycles are useful tests to assess the durability of the earthen plasters when exposed to the external environment. The first two types of the cycle are usually set up for other materials (such as cement) and are too severe for the earthen materials [79]. The exposition of earthen materials to moisture and daily thermal variation may cause swelling and shrinkage of clay minerals with expandable lattice causing physical damage. Thermo-hygrometric cycles are suitable to investigate the durability of earthen plasters. An Angelantoni Challenge 500 Climatic Chamber was used and the thermo-hygrometric conditions changed according to the cycle reported in Figure 3. This cycle was repeated 50 times. Colorimetric and weight measurements were done before and after the thermo-hygrometric cycles.

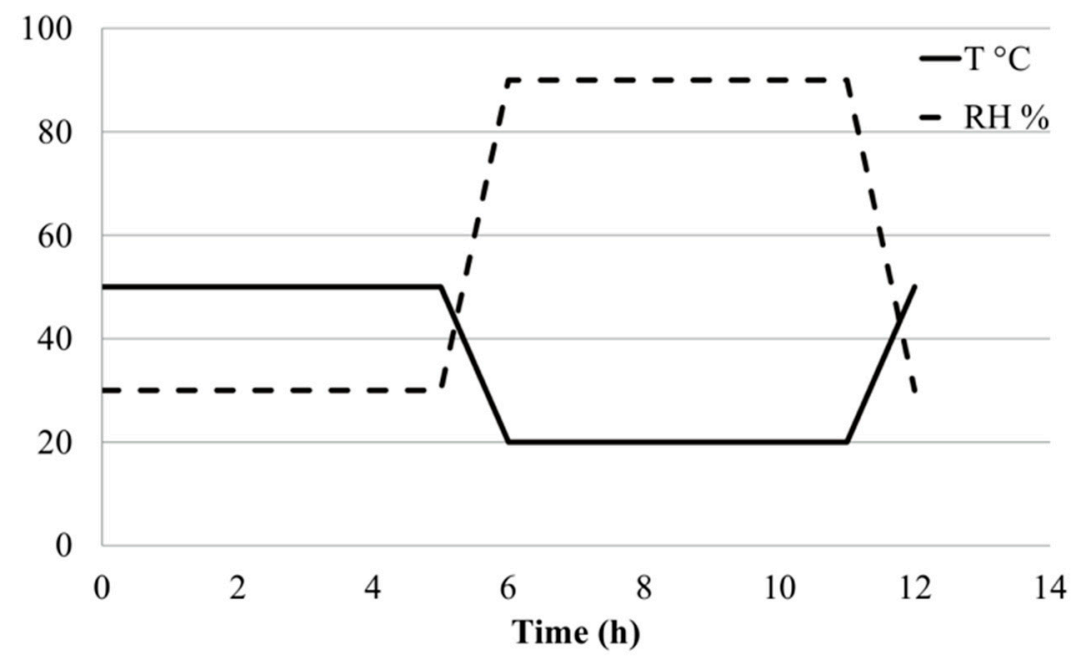

Figure 3. Thermo-hygrometric cycle (credit Silvia Rescic).

\section{Results}

\subsection{Presence of New Phases and Residues of the Original Additives}

After the addition of the various additives, the XRD analysis was carried out on the total fraction of the earth to verify the possible formation of new phases and the presence of residues from the original additives. After 45 days of curing, the following minerals were observed (Figures 4A, 5A, 6A, 7A, 8A and 9A):

- calcite and portlandite in earth plasters + cement kiln dust and earth + slaked lime;

- $\quad$ gypsum in the earth plasters $+5 \%$ and $20 \%$ plaster of Paris;

- portlandite in traces in the case of earth plaster + slaked lime;

- $\quad$ neither new phases are evident in the earth plaster + enzymatic solution and earth + geopolymer solution, nor dangerous compounds, such as $\mathrm{Na}_{2} \mathrm{CO}_{3}$ and $\mathrm{KHCO}_{3}$ carbonates, also after one year of curing are detected [25] (Figures 4B, 5B, 6B, 7B, 8B and 9B). 


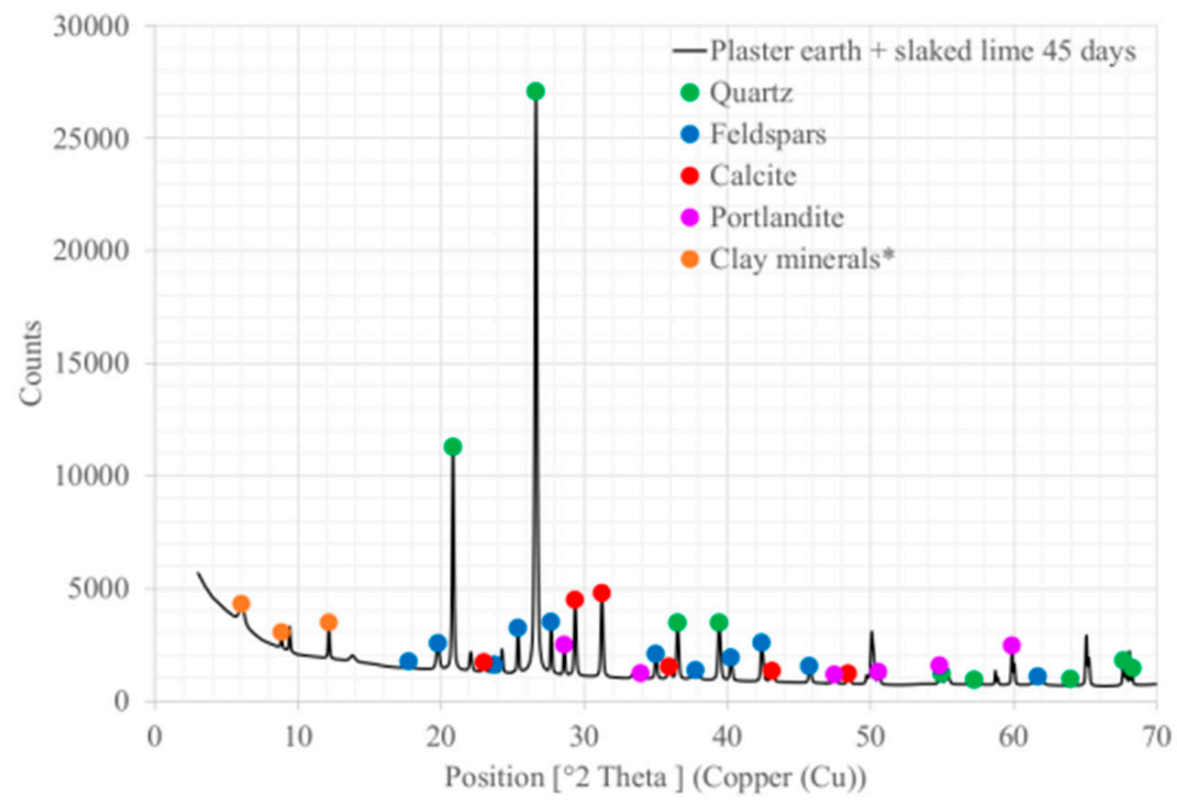

(A)

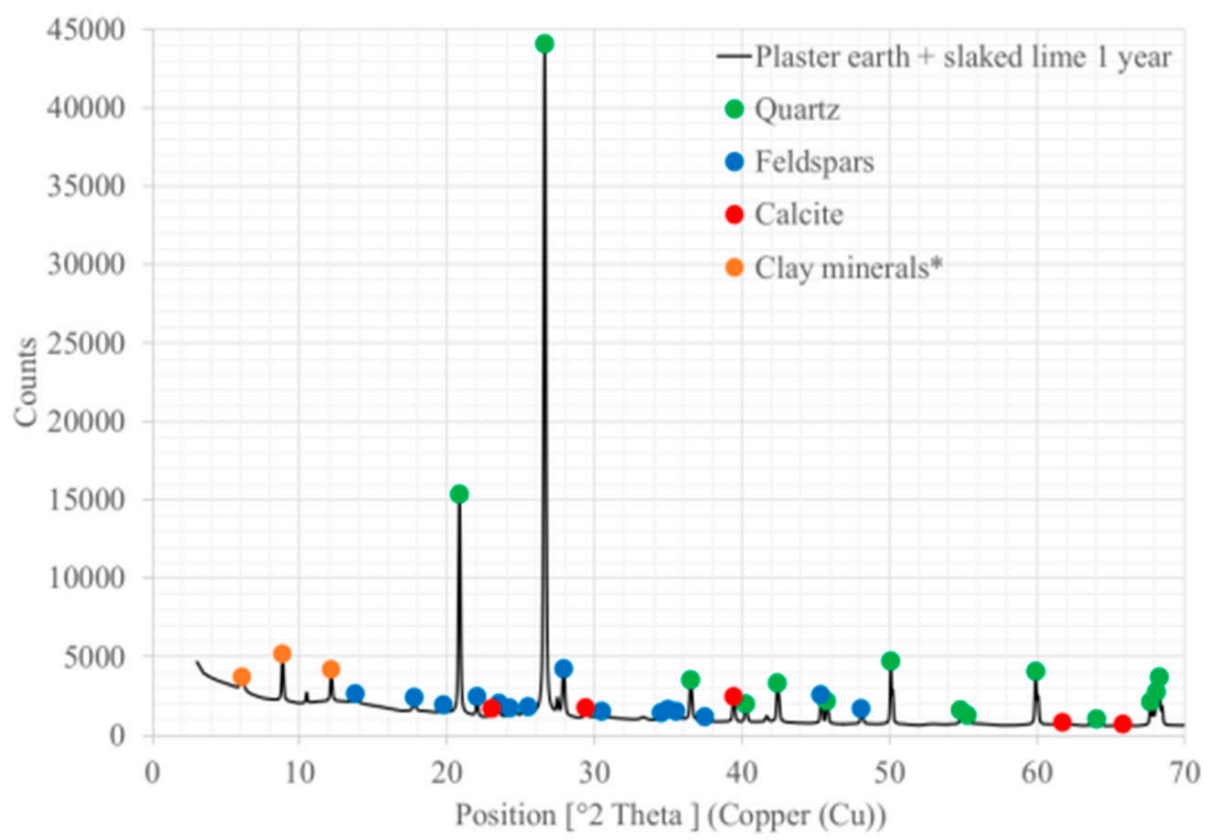

(B)

Figure 4. XRD spectra of the plaster earth + slaked lime: principal mineralogical composition after 45 (A) and after 1 year (B); ${ }^{*}$ plus other phases (credit Silvia Rescic). 


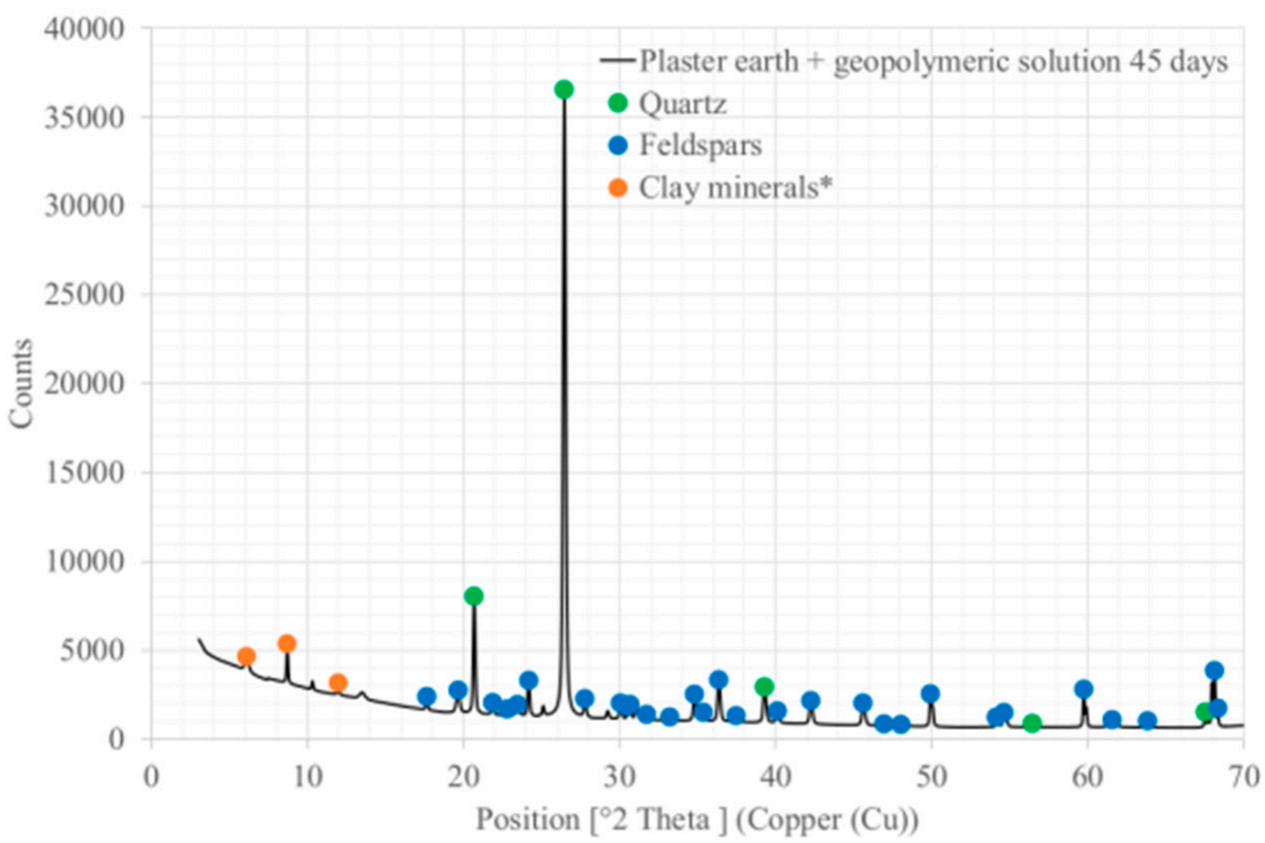

(A)

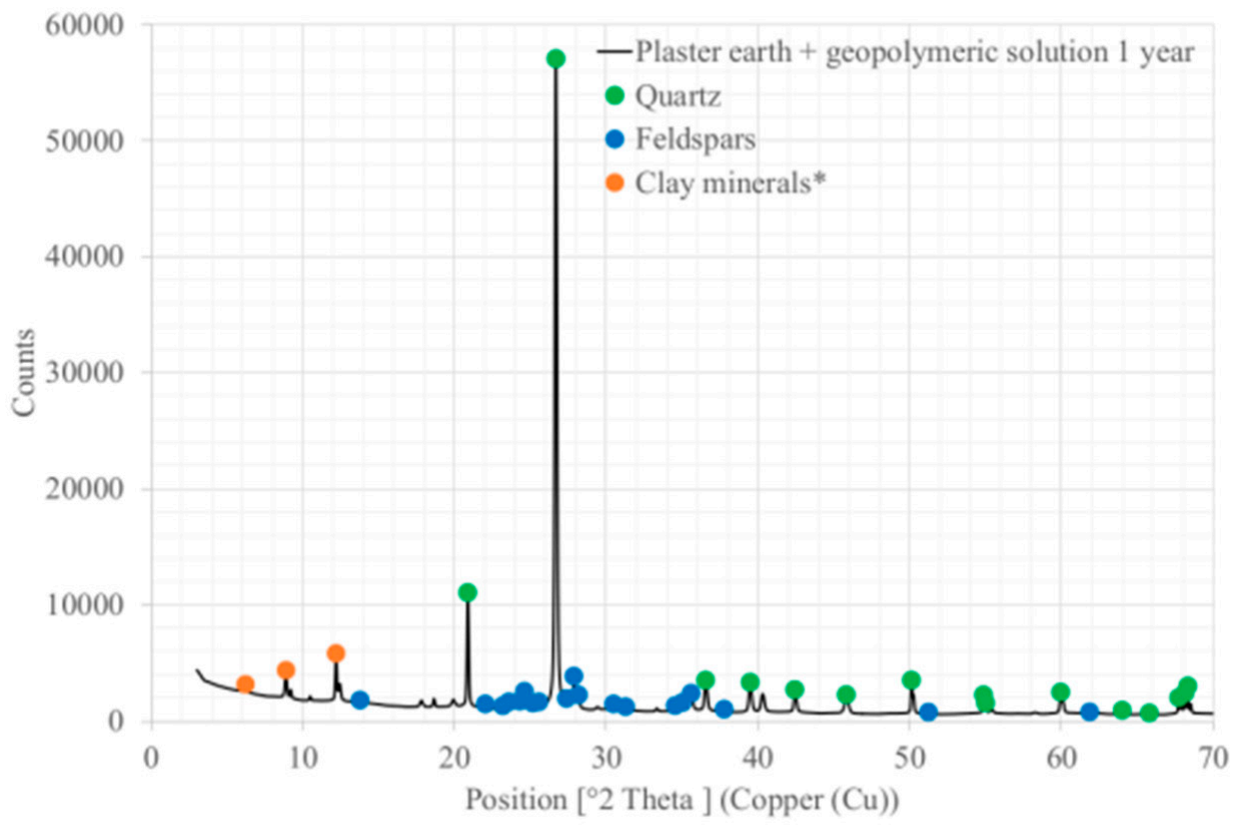

(B)

Figure 5. XRD spectra of the plaster earth + geopolymeric solution: principal mineralogical composition after 45 (A) and after 1 year (B); ${ }^{*}$ plus other phases (credit Silvia Rescic). 


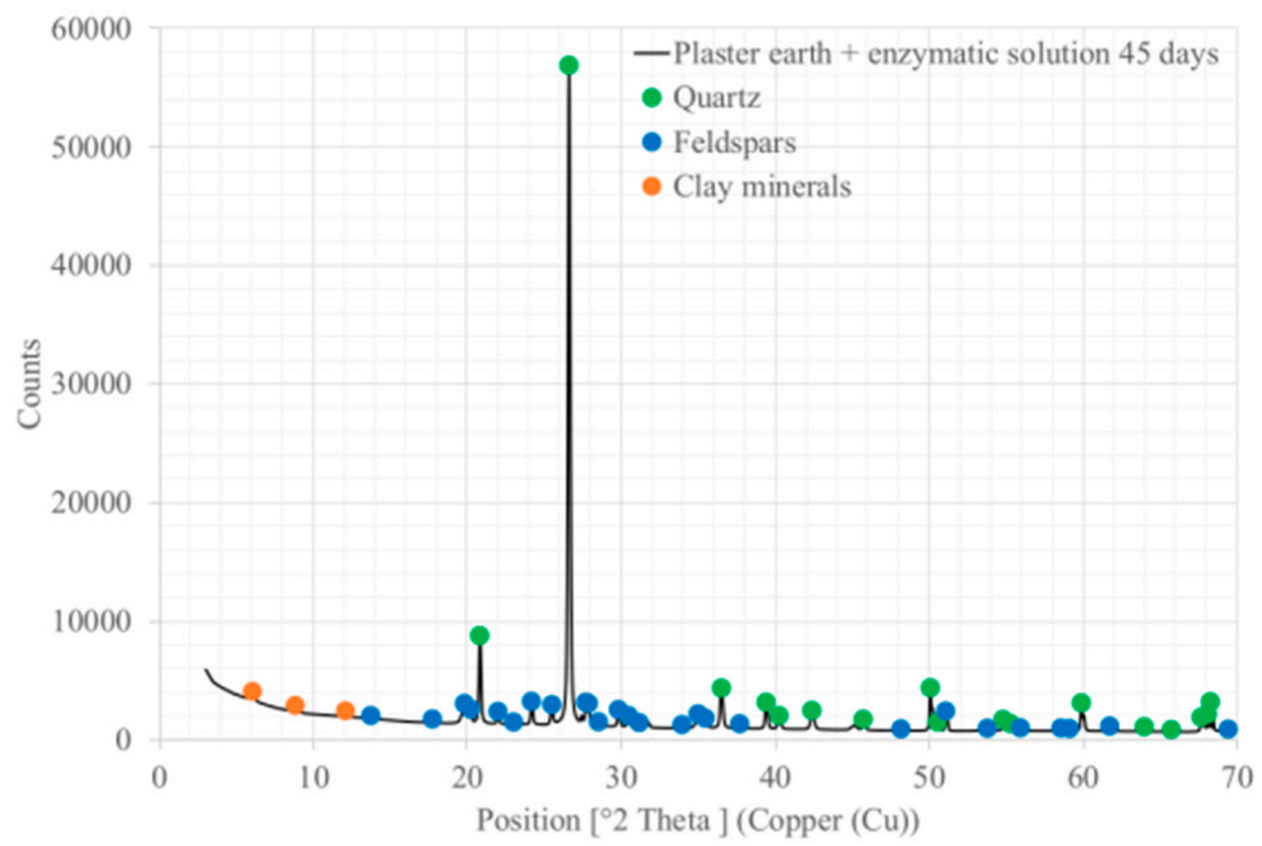

(A)

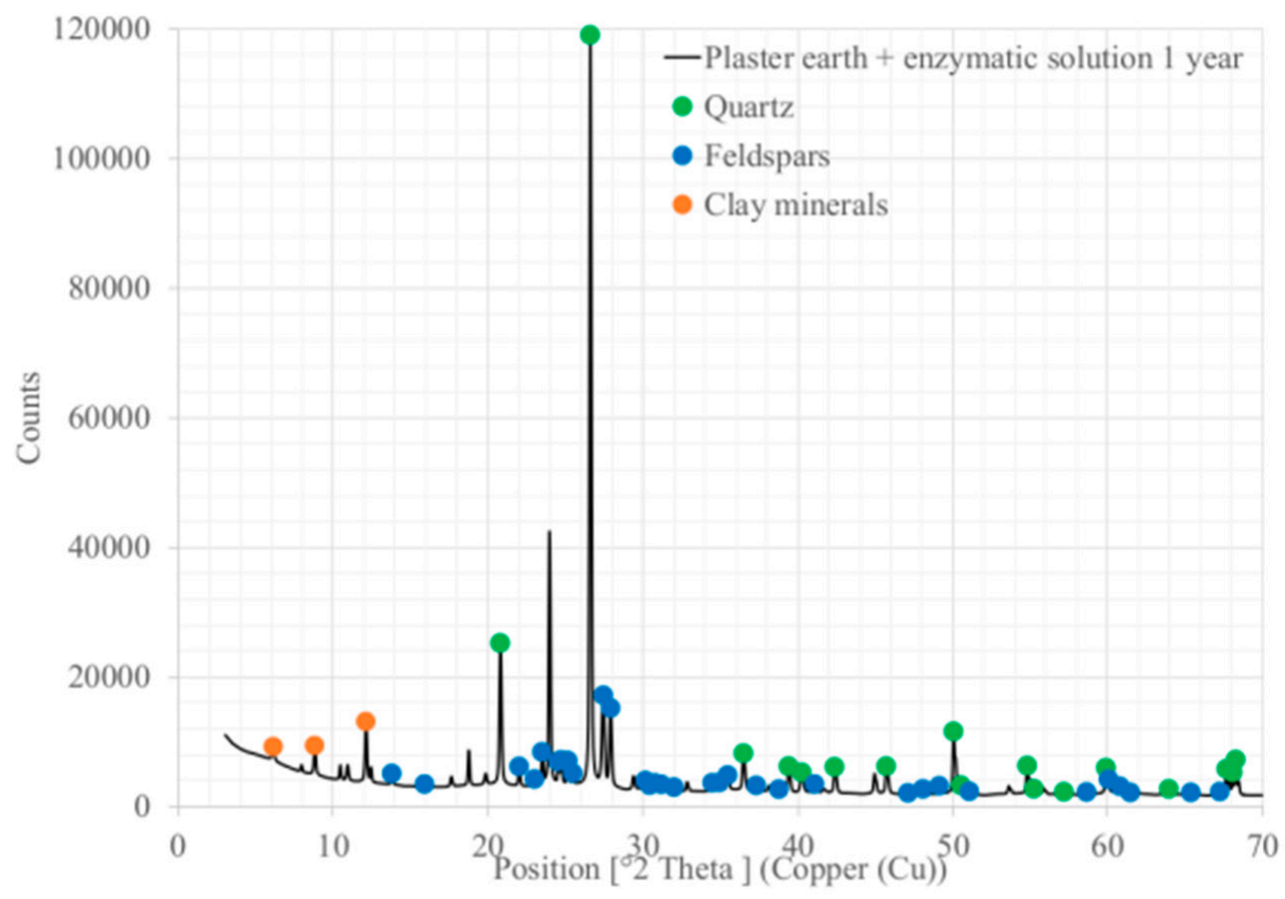

(B)

Figure 6. XRD spectra of the plaster earth + enzymatic solution: principal mineralogical composition after 45 (A) and after 1 year (B) (credit Silvia Rescic). 


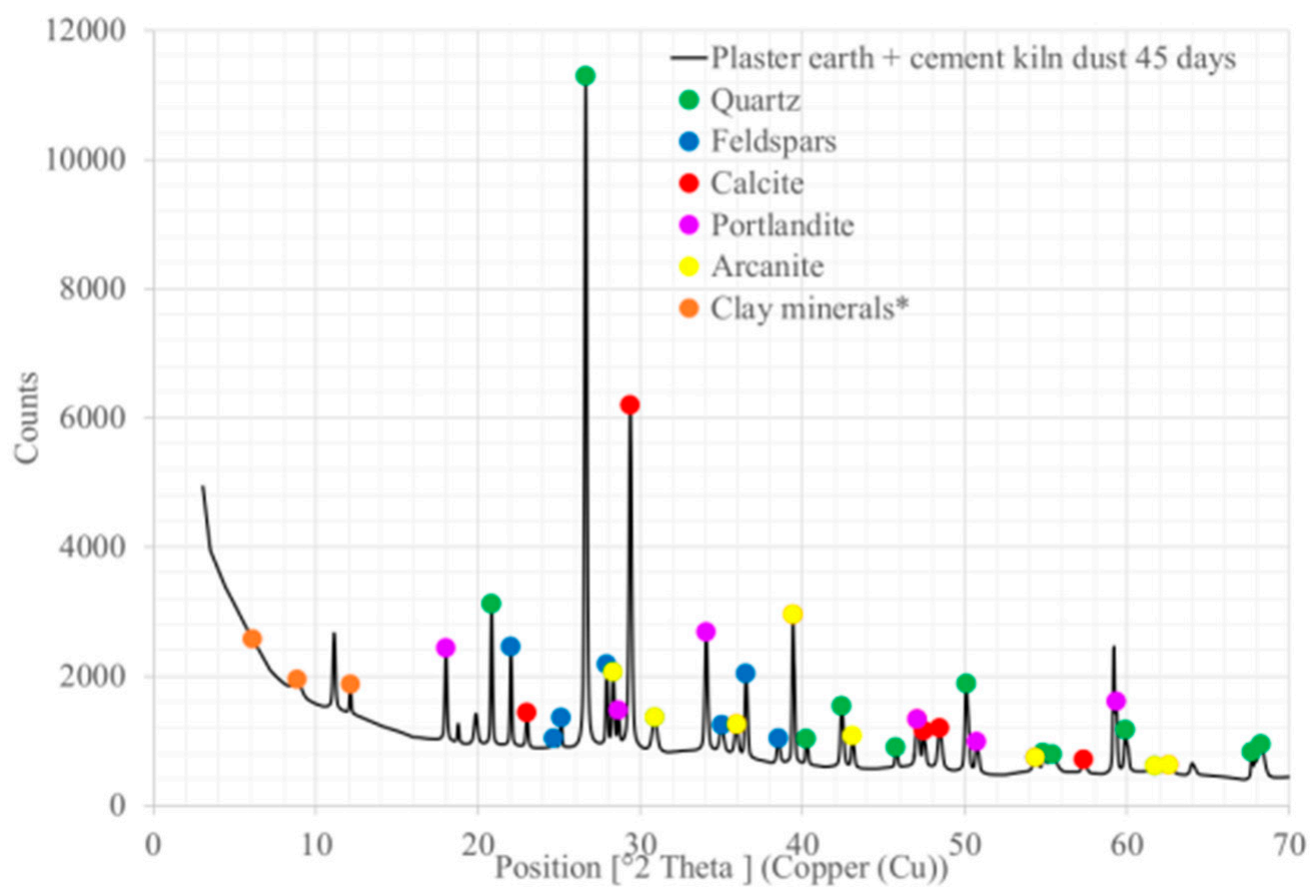

(A)

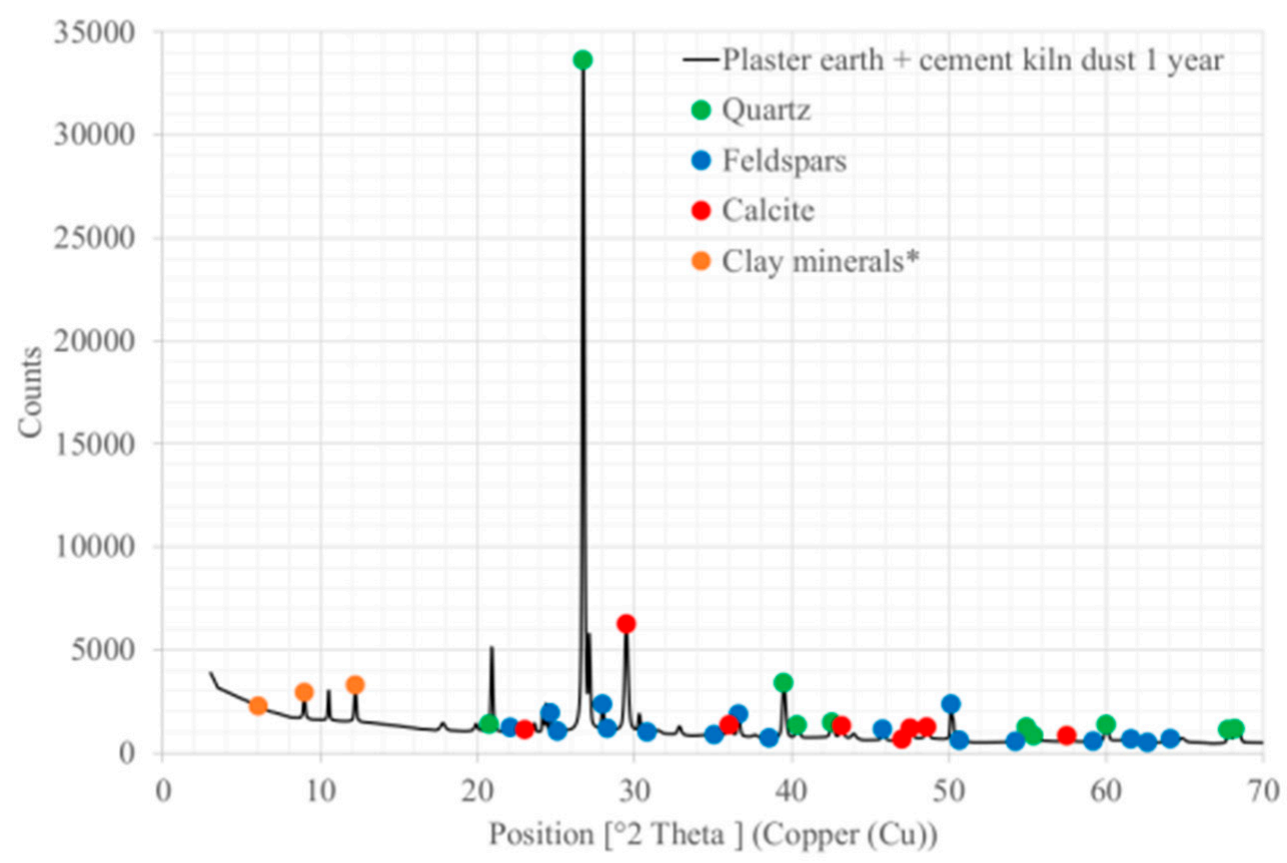

(B)

Figure 7. XRD spectra of the plaster earth + cement kiln dust: principal mineralogical composition after 45 (A) and after 1 year (B); ${ }^{*}$ plus other phases (credit Silvia Rescic). 


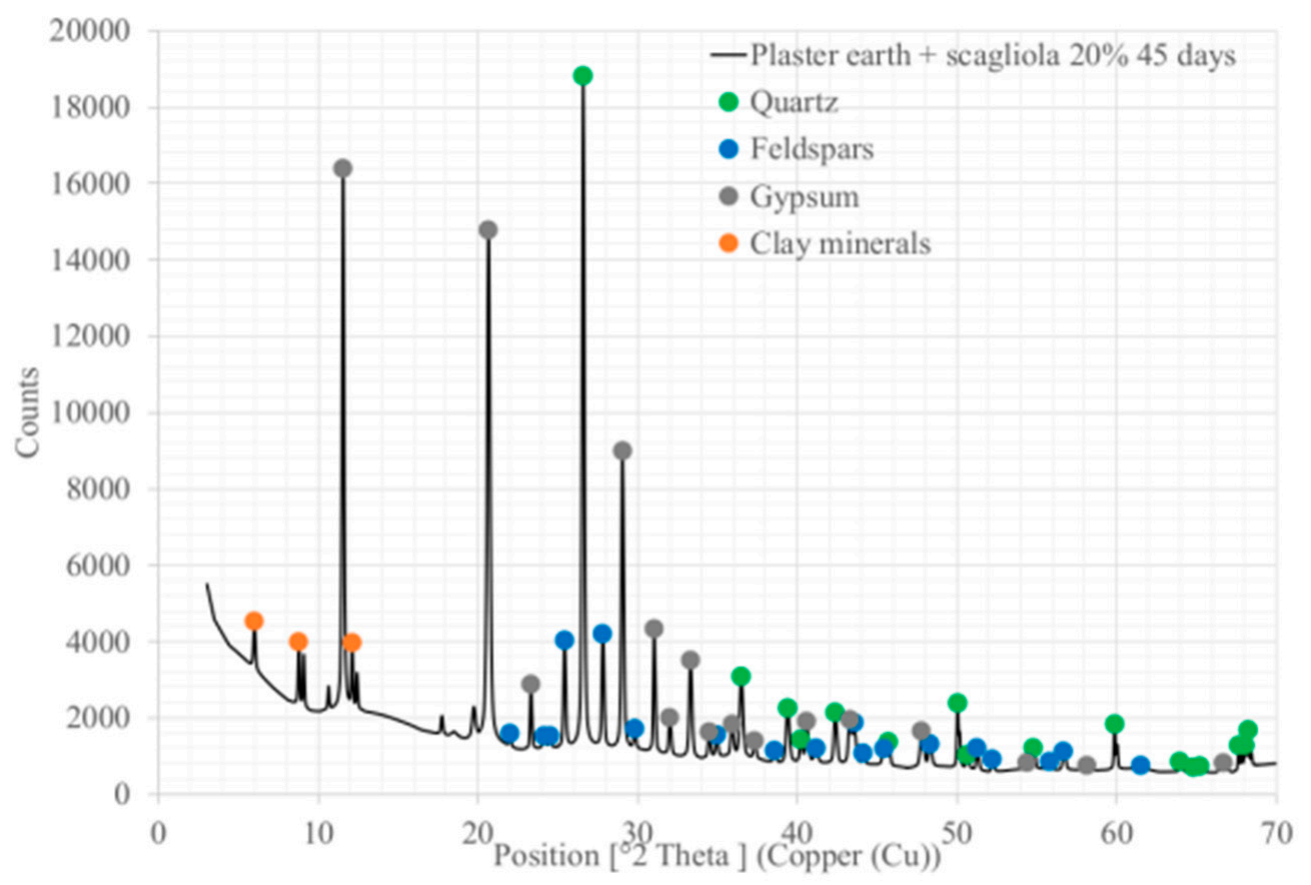

(A)

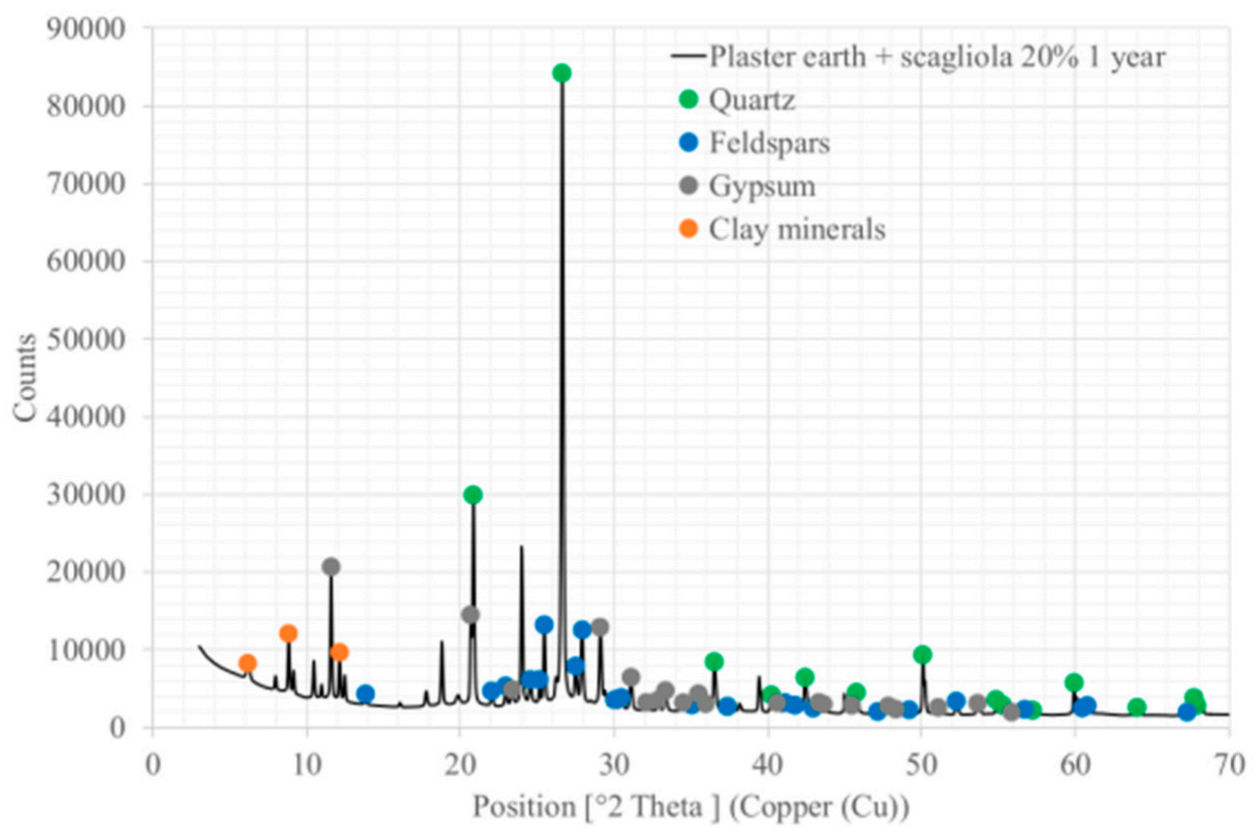

(B)

Figure 8. XRD spectra of the earth $+20 \%$ plaster of Paris: principal mineralogical composition after 45 days (A) and after 1 year (B) (credit Silvia Rescic). 


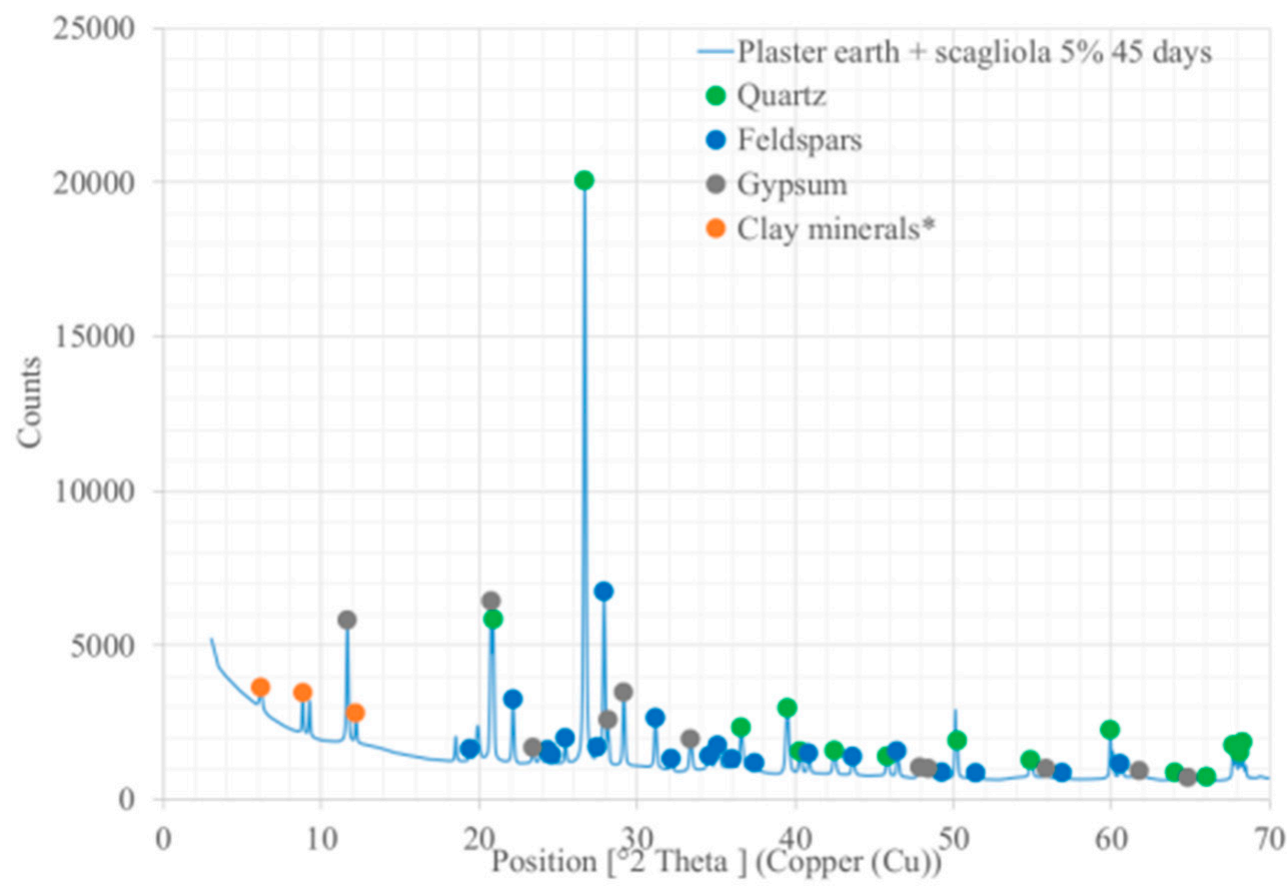

(A)

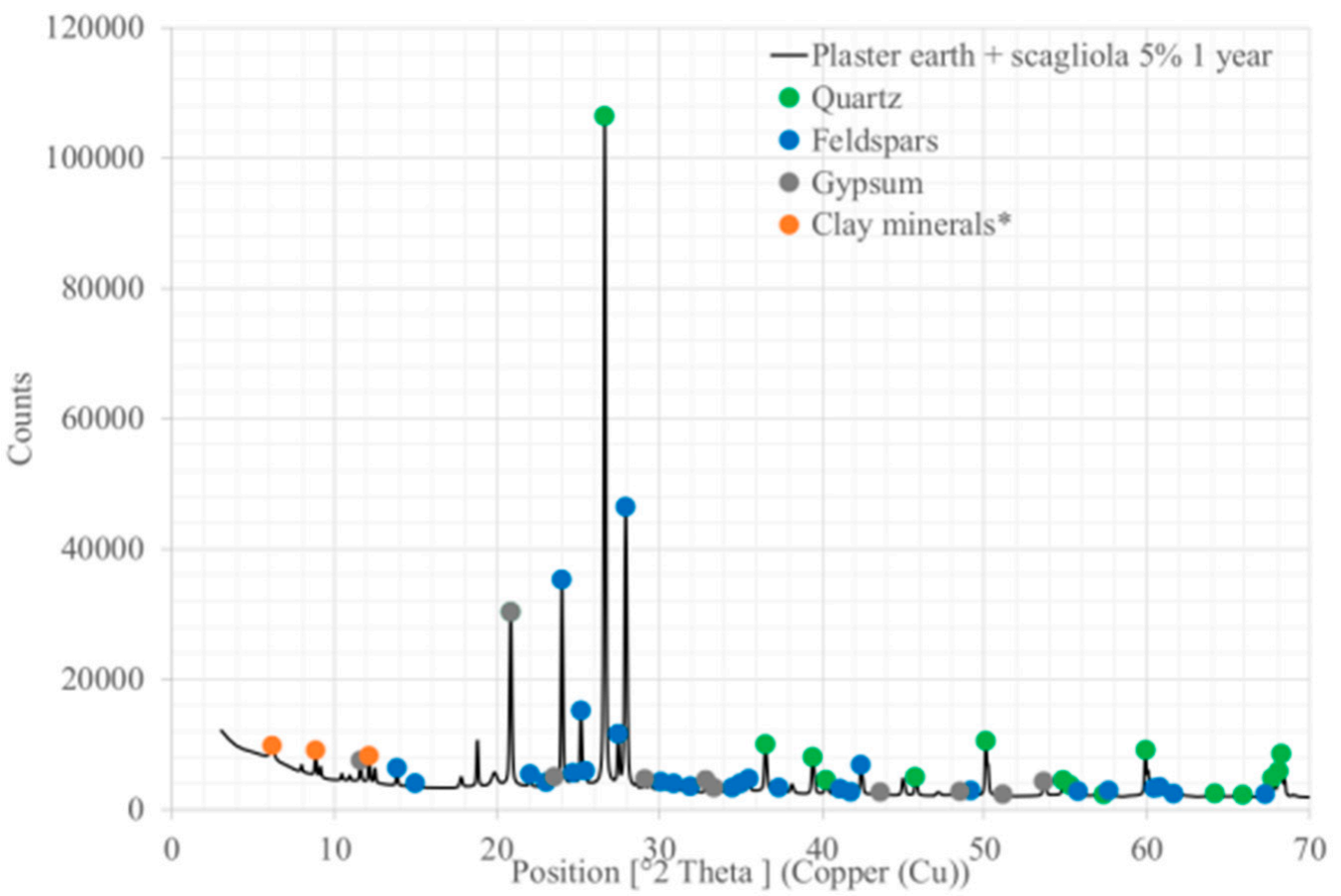

(B)

Figure 9. XRD spectra of the earth $+5 \%$ plaster of Paris: principal mineralogical composition after 45 days (A) and after 1 year (B); * plus other phases (credit Silvia Rescic). 
After a year of curing, portlandite is no longer present in the case of earth + slaked lime and earth + cement kiln dust. For the other plasters, no changes are observed in comparison with the 45-day spectrum.

In the case of plasters stabilized with CKD, the presence in traces of arcanite at 45 days has been detected. This phase is no more present after one year. The possible explanation is the migration of this compound towards the surface of the plaster as evidenced by the presence of a whitish powder after 45 days. This powder was mechanically removed with a soft brush, and no more efflorescence was evidenced after one year. Nevertheless, as regards to the presence of sulfates, the balance between advantages (positive performance) and disadvantages (possible damage) of using CKD must be evaluated.

3.1.1. Presence of New Phases and Residues of the Original Additives in the Separated Clay Fraction

The presence of neoformation phases, related to the additives reacting with clay minerals, was verified also in the separated clay fraction, the one reactive towards the additives. The results are the following (Figure 10):

- the sample with the addition of slaked lime after 45 days shows the presence of the original clay minerals namely smectite-montmorillonite $\left(\mathrm{d}=14.54 \AA\right.$, $2 \theta=6.07^{\circ}$, XRD ICDD card: 00-007-0051), kaolinite: $d=7.17 \AA, 2 \theta=12.34^{\circ}$, XRD ICDD card: 00-007-0051, 01-089-6538), and illite ( $\mathrm{d}=10.00 \AA 2,2 \theta=8.84^{\circ}$, XRD ICDD card. 00026-0911) together with the presence of two new peaks $\left[d=12.42 \AA\left(2 \theta=7.11^{\circ}\right)\right.$ and $\left.\mathrm{d}=11.14 \AA\left(2 \theta=7.93^{\circ}\right)\right]$ to be referred to respectively Zeolite 5A (XRD ICDD card: 01-072-0083) and Clinotobermorite (XRD ICDD card: 01-088-1328). Such peaks are present also after one year together with the disappearance of the peak relative to smectite-montmorillonite;

- the sample with the addition of the geopolymeric solution after 45 days shows the presence of the original clay minerals (smectite-montmorillonite, kaolinite, and illite). One year later, two new peaks, to be referred to zeolite phases, are observed. The peaks close to that of smectite/montmorillonite $\mathrm{d}=14.54 \AA\left(2 \theta=6.07^{\circ}\right)$ at $\mathrm{d}=14.30 \AA$ $\left(2 \theta=6.17^{\circ}\right)$, and the other at $d=11.18 \AA\left(2 \theta=7.91^{\circ}\right)$, should be referred to the potassic Faujasite-K (XRD ICDD card: 00-026-0894) and Zeolite ZSM-5 (XRD ICDD card: 01-079-2401);

- the sample with the addition of CKD after 45 days shows the disappearing of the peak relative to smectite-montmorillonite, while the peaks of kaolinite and illite are still present. Moreover, new little peaks to be referred to zeolite phases (Zeolite 5A, Faujasite-K) and clinotobermorite can be observed. After one year of curing, these zeolite peaks are more evident.

The results of the TG analysis after one year of curing, and the first derivative of the TG curves (DTG), are reported in Figure 11, while in Table 3, the ranges of temperature relative to the main transformations are reported [80-90]. As evidenced in the table, many overlaps are present among the thermal processes relative to the clay minerals and those of the zeolites, causing some ambiguities in the interpretation of the peaks. 


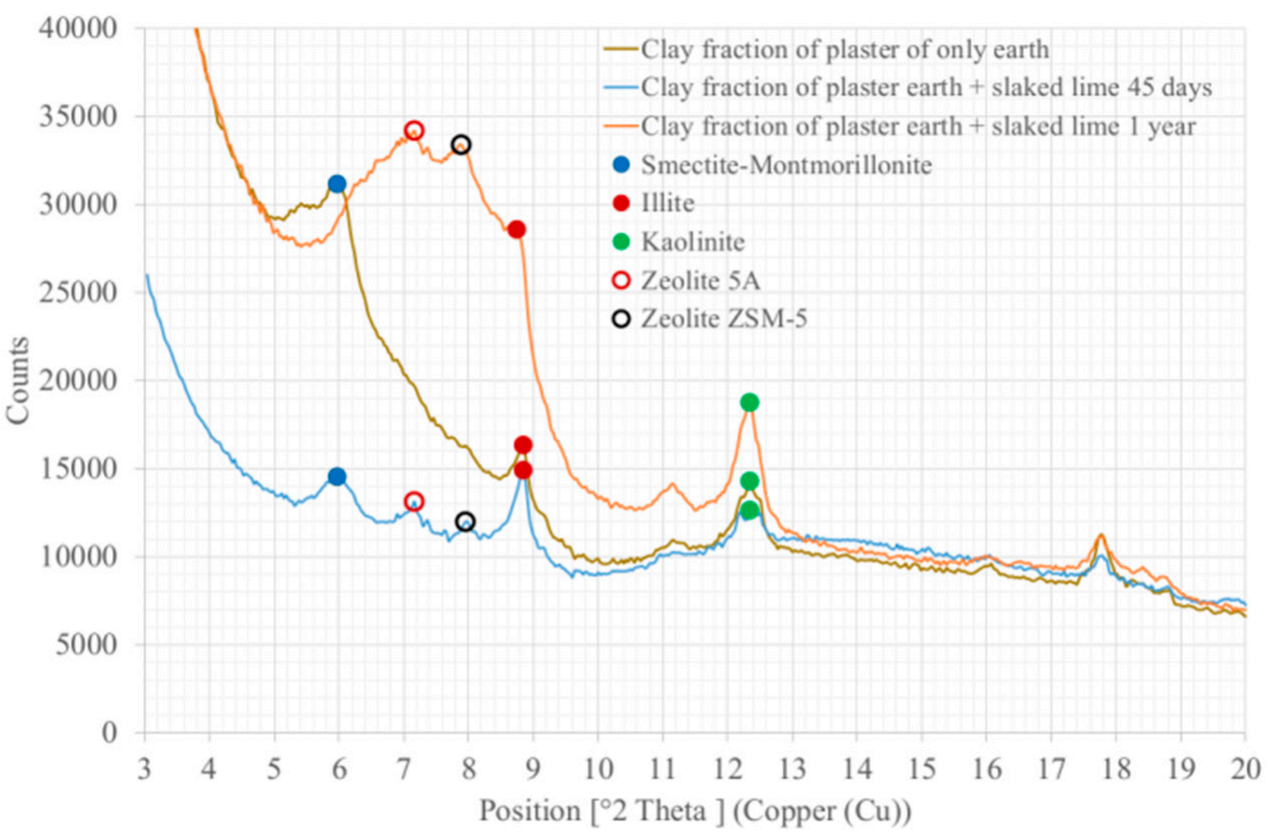

(A)

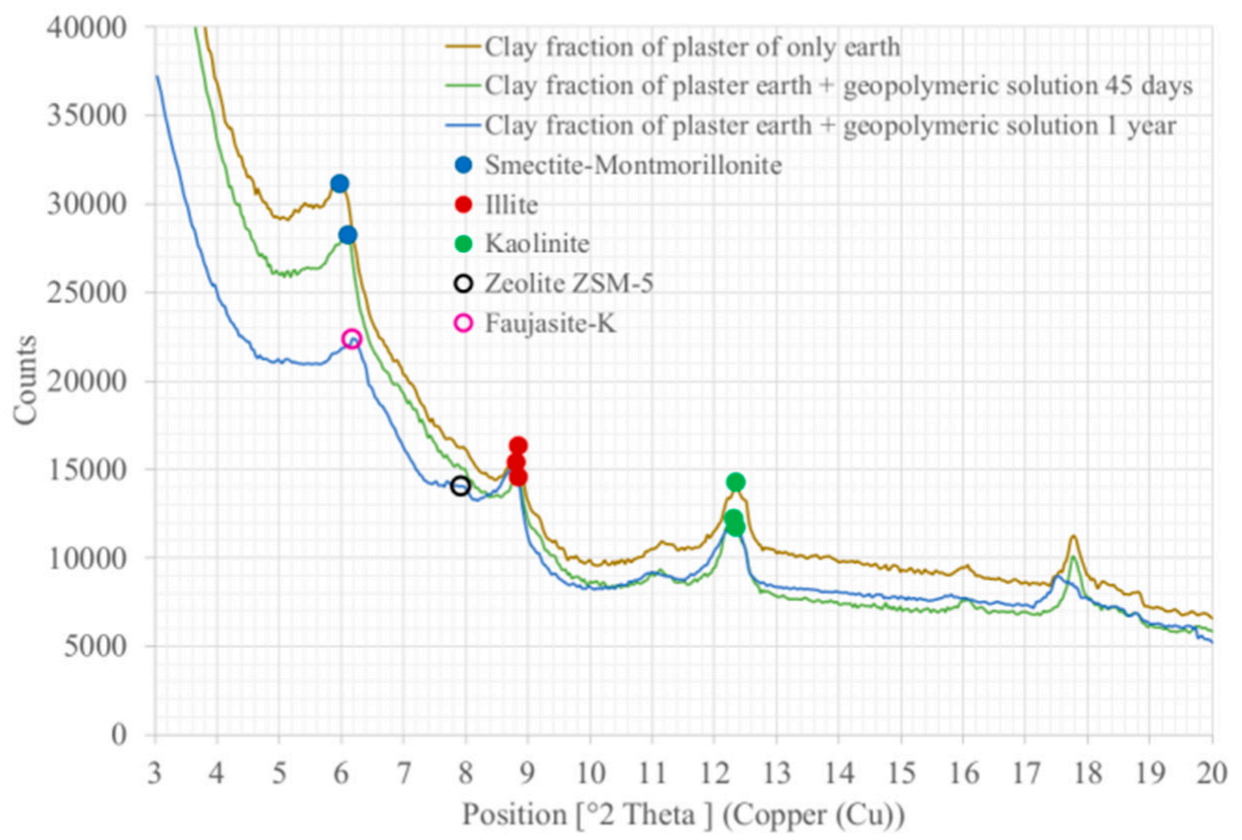

(B)

Figure 10. Cont. 


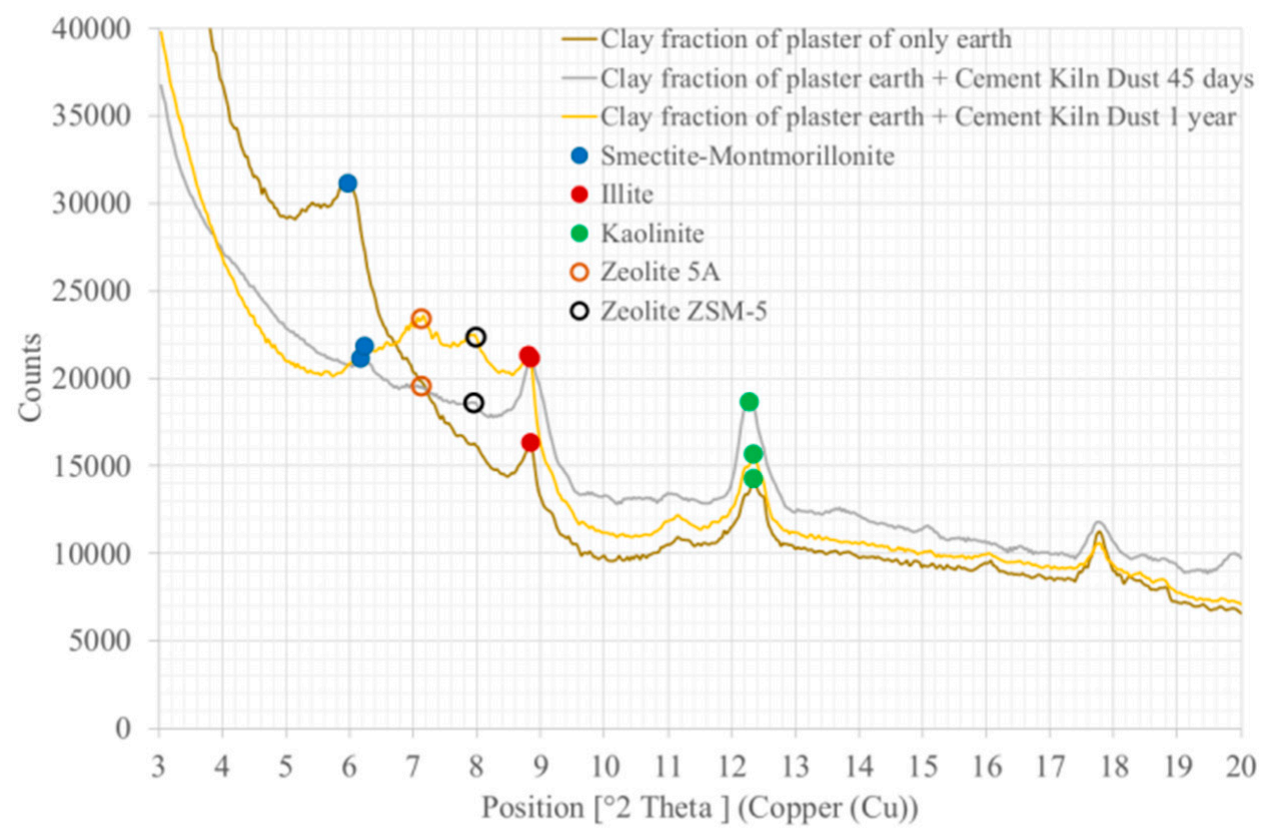

(C)

Figure 10. XRD spectra on the clay fraction of plaster with slaked lime (A), with geopolymeric solution (B), and with cement kiln dust (C) after 45 days and 1 year of curing respect to earth-only the plaster (credit Silvia Rescic).

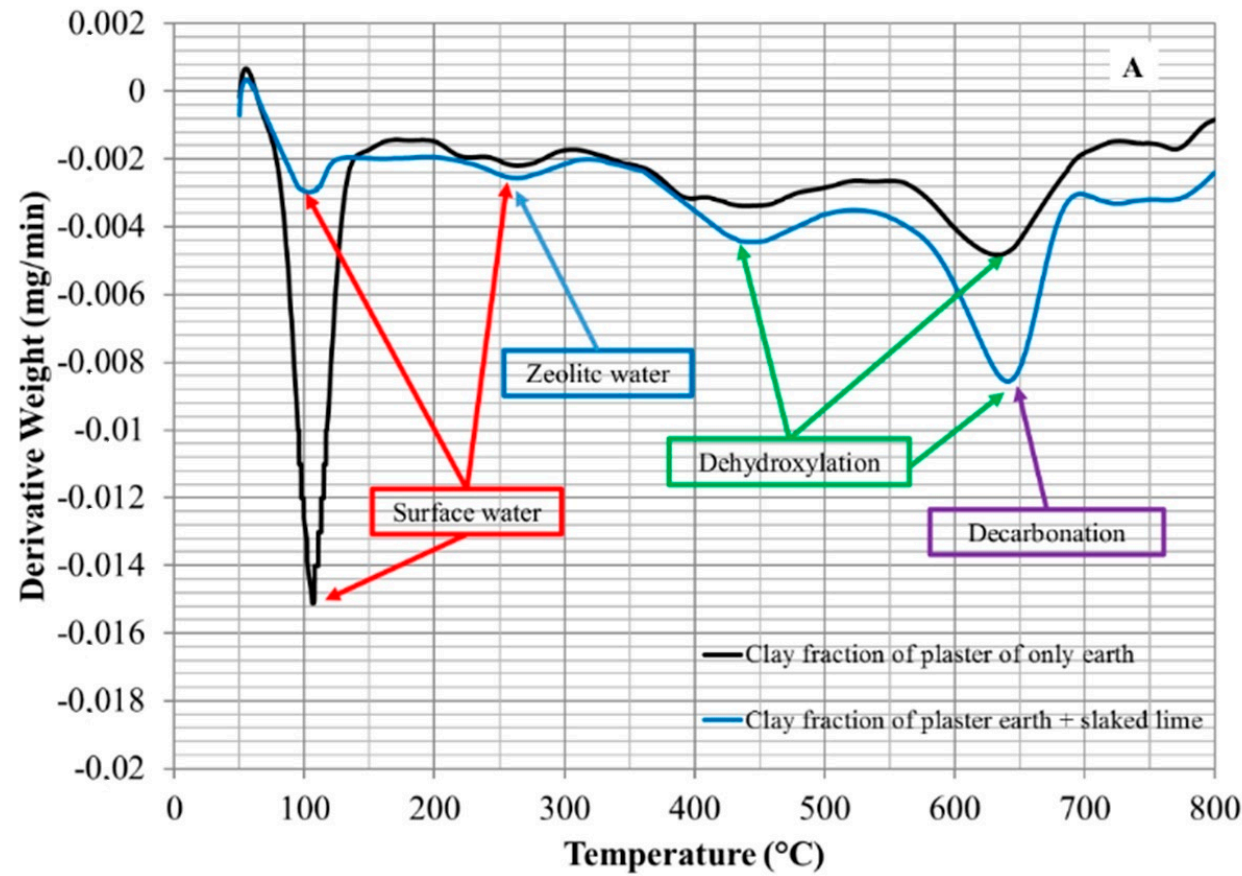

Figure 11. Cont. 

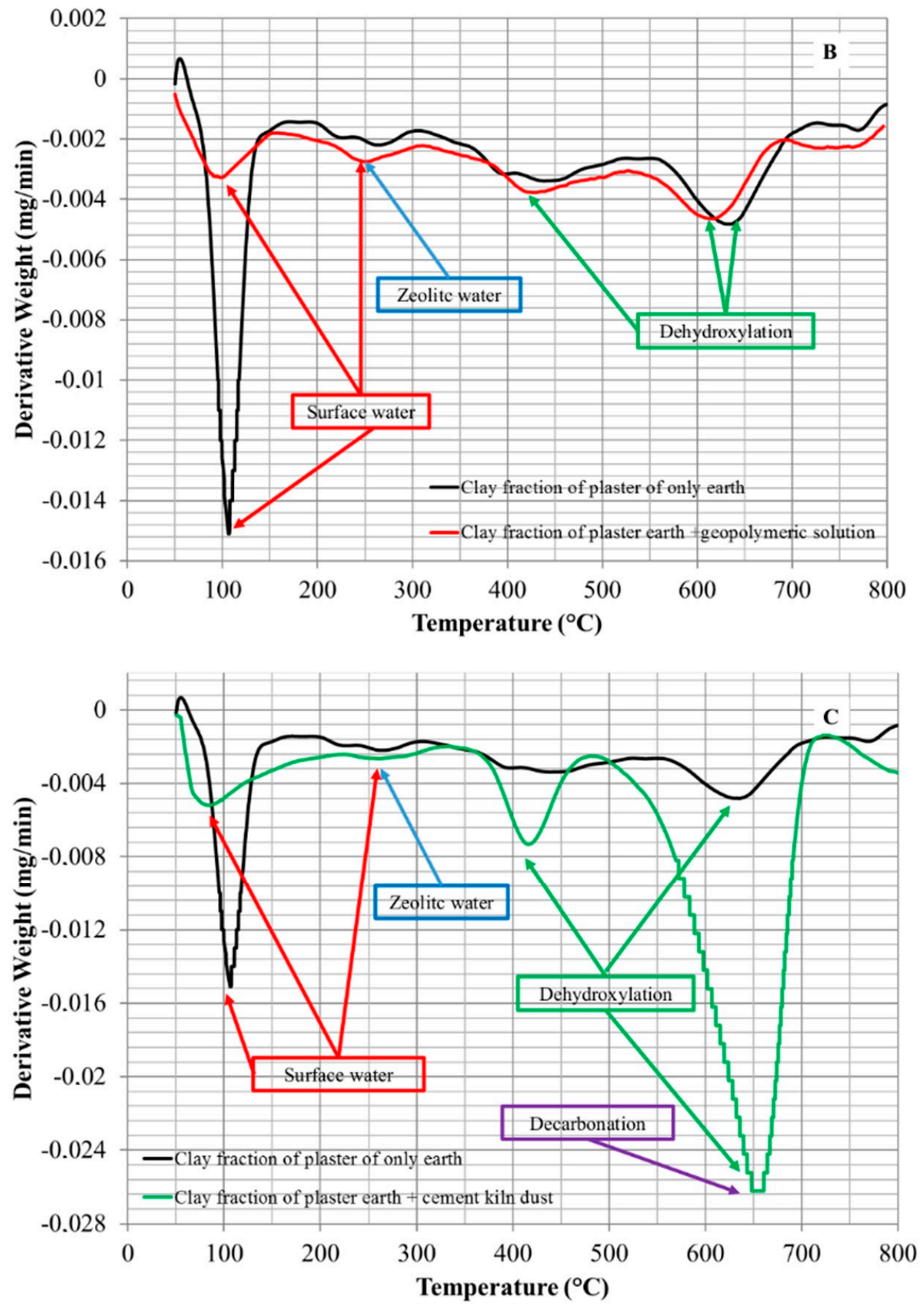

Figure 11. DTG diagram of clay fraction of plaster earth + slaked lime (A), plaster earth + geopolymeric solution (B), and plaster earth + cement kiln dust (C) after one year of curing, compared with the one of the clay fractions of earth-only plaster (credit Silvia Rescic). 
Table 3. Temperature ranges of main thermal processes for thermogravimetric analysis.

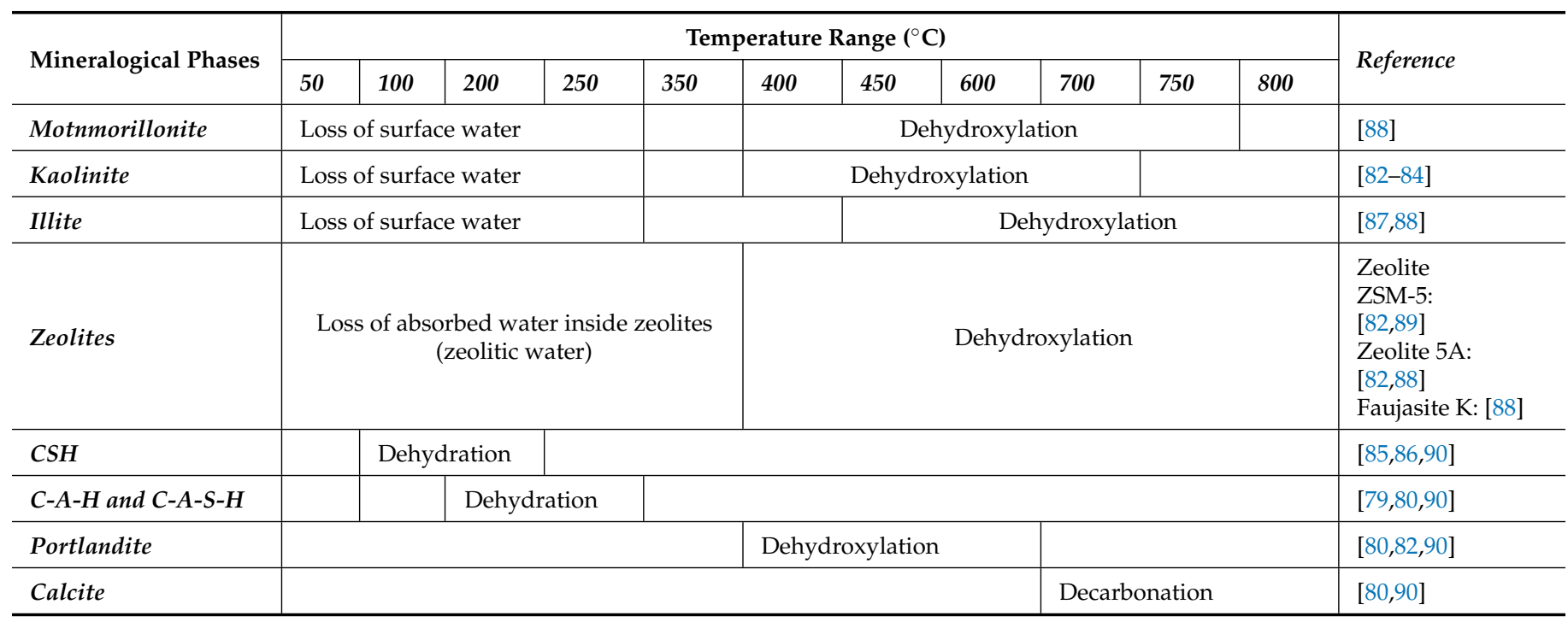

In Figure 11A, the diagram relative to clay fraction + slaked lime is represented. The following reactions can be evidenced:

- in the range $50-150{ }^{\circ} \mathrm{C}$, the peak around $100{ }^{\circ} \mathrm{C}$ (loss of surface water) is attenuated compared to that of the clay minerals of the earth alone and could indicate a lower presence of clay phases. Nothing can be said about the presence of CSH or zeolitic phases;

- in the range $200-300{ }^{\circ} \mathrm{C}$ (loss of surface water and/or zeolitic water), there is a slightly more evident peak, compared to that of the earth alone, attributable to the presence of zeolites together with the remaining clay mineral phases; this range can also have loss of water of crystallized salts or due to some iron or aluminum amorphous hydrates, but in the one-year XRD are not evidence of these compounds;

- in the range $400-500{ }^{\circ} \mathrm{C}$, the little peak (dehydroxylation) can be attributed to the remaining clay minerals and the new zeolitic phases. It cannot be referred to portlandite because such phase is not present in the X-ray diffraction analysis after one year of curing;

- in the range $600-700{ }^{\circ} \mathrm{C}$, the most pronounced peak, compared to that of the clay fraction of the earth-only, suggests that the dehydroxylation process of the remaining clay minerals and the new zeolite phases is superimposed on that of calcite decarbonation, identified by the $X$-ray diffraction analysis on the total earth at 45 days and after one year of curing.

In Figure 11B, the diagram relative to clay fraction + geopolymeric solution is represented. The following reactions can be evidenced:

- in the range $50-150{ }^{\circ} \mathrm{C}$, the peak around $100{ }^{\circ} \mathrm{C}$ (loss of surface water) is attenuated compared to that of the clay fraction of the earth alone and could indicate a lower presence of clay minerals, while it is not possible to give indications for the presence of zeolitic phases;

- in the range $200-300{ }^{\circ} \mathrm{C}$ (loss of surface water and/or zeolitic water), there is a slightly more evident peak, compared to that of the clay fraction of the earth alone, referred to the presence of zeolites together with the remaining clayey phases; this range can also have loss of water of crystallized salts or due to some iron or aluminum amorphous hydrates but in the one-year XRD are not evidence of these compounds;

- in the range $400-500{ }^{\circ} \mathrm{C}$, the peak around $450{ }^{\circ} \mathrm{C}$ (dehydroxylation) can be attributed to the remaining clay minerals and the new zeolite phases; 
- in the range $600-700{ }^{\circ} \mathrm{C}$, the most pronounced peak, compared to that of the clay fraction of the earth alone, suggests that the dehydroxylation process of the remaining clay minerals is superimposed to that of the new zeolitic phases.

In Figure 11C, the diagram relative to clay fraction + cement kiln dust is represented. The following reactions can be evidenced:

- in the range $50-150{ }^{\circ} \mathrm{C}$, the peak around $100^{\circ} \mathrm{C}$ (loss of surface water) is very attenuated, compared to that of the clay fraction of the earth alone, making us suppose a lower presence of clay minerals; nothing can be said about the presence of CSH or zeolitic phases;

- in the range $200-300^{\circ} \mathrm{C}$ (loss of surface water and/or zeolitic water), the trend of the thermal curve is very similar to that of the clay fraction of the earth alone, with a mild loss of water to be referred to clay minerals or new zeolitic phases; this range can also have loss of water of crystallized salts or due to some iron or aluminum amorphous hydrates but in the one-year XRD are not evidence of these compounds;

- in the range $400-500{ }^{\circ} \mathrm{C}$, the most evident peak (dehydroxylation), compared to that of the clayey fraction of the earth alone, can be attributed the new zeolitic phases and to the remaining clay minerals. It is not possible to attribute the peak to portlandite as it is not present in the X-ray diffraction analysis on the total earth after one year of curing;

- in the range $600-700{ }^{\circ} \mathrm{C}$, the much more pronounced peak, to that of the clayey fraction of the earth alone, suggests that the dehydroxylation process of the remaining clay minerals and the zeolite phases is superimposed on that of calcite decarbonation, identified from the X-ray diffraction analysis on the total earth at 45 days and after one year of curing.

\subsubsection{Performance of the Earthen Plaster Mixtures}

According to the results of the Geelong test, the erodibility indices (Table 4) vary between 2 (minimum erosion) and 4 (fail). Plasters $\mathrm{D}$ and $\mathrm{E}$ were not eroded; plaster $\mathrm{A}$ reached an erosion index of 2, while plasters $B, C$, and F displayed a higher degree of erosion with an index of 3 , similar to the samples without any stabilizer. The performance of plaster $C$ was the worst, with an erosion index of 4 .

Table 4. Geelong test on earthen plaster mixtures: mean values of depth of the hole and erosion index.

\begin{tabular}{ccc}
\hline Sample ID & Depth of the Hole $(\mathbf{m m})$ & Erosion Index \\
\hline Earth & $9.6 \pm 0.2$ & 3 \\
A & $3.6 \pm 0.4$ & 2 \\
B & $9.3 \pm 0.6$ & 3 \\
C & $10.3 \pm 0.7$ & 4 \\
D & 0 & 2 \\
E & 0 & 2 \\
F & $9.3 \pm 0.7$ & 3 \\
\hline
\end{tabular}

A = earth + slaked lime; B = earth + geopolymeric solution; C = earth + enzymatic solution; $\mathbf{D}=$ earth + cement kiln dust; $\mathbf{E}=$ earth $+20 \%$ plaster of Paris; $\mathbf{F}=$ earth $+5 \%$ plaster of Paris.

The results of the spray erosion tests are shown in Figure 12A. The diagram provides the linear regression lines evaluated through the measurement of the erosion depth recorded during the test every 15 -min interval. 


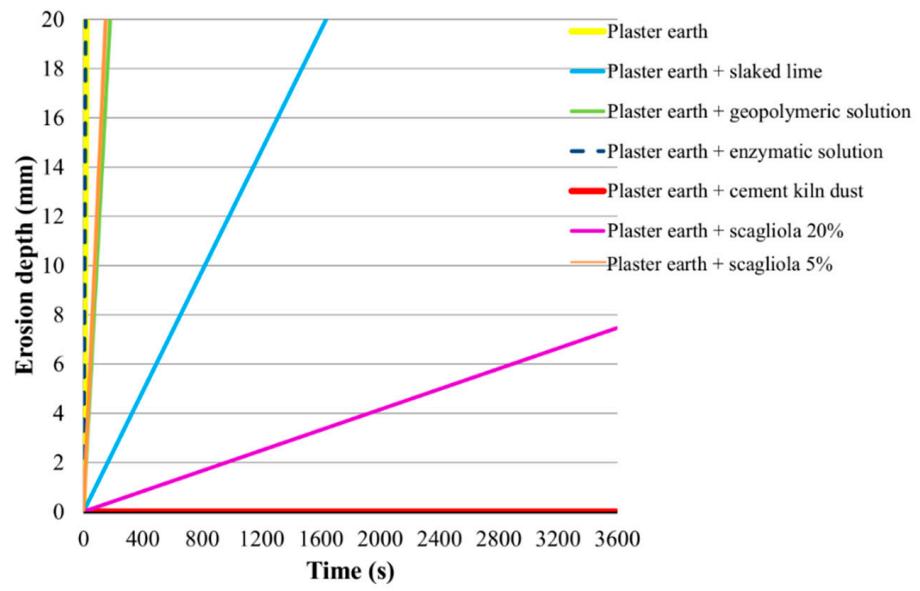

(A)

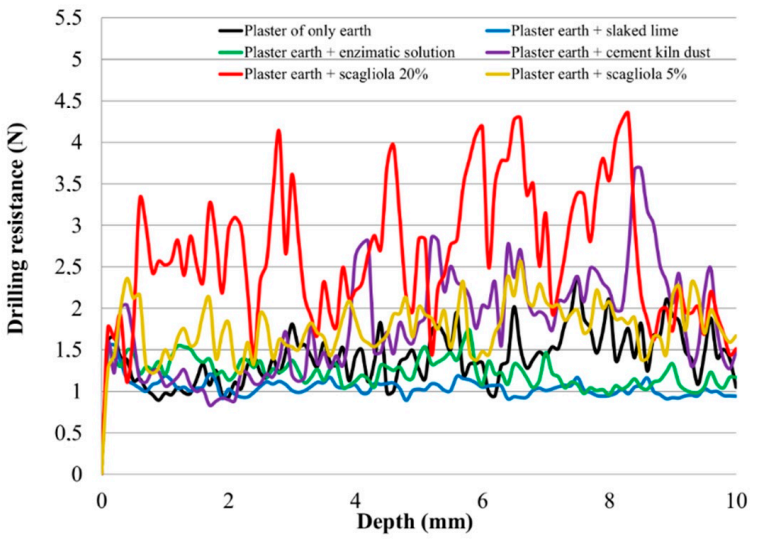

(B)

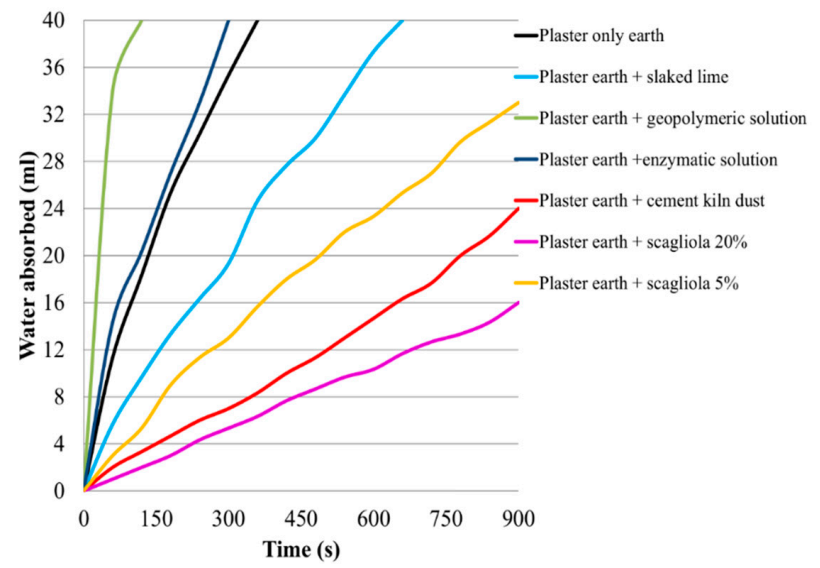

(C)

Figure 12. Diagram illustrating the results of erosion spray tests as regression lines of treated and earth-only plasters (credit Manuela Mattone) (A); Drilling resistance mean profiles of treated and earth-only plasters (credit Silvia Rescic) (B); Water absorption through the Karsten method of treated and earth-only plasters (credit Manuela Mattone) (C). 
Plaster D (CKD) shows the greatest resistance not being affected by any erosion after 60 min; plaster E with 20\% plaster of Paris, shows good resistance, with an erosion depth of $7 \mathrm{~mm}$ after $60 \mathrm{~min}$. Plaster A (only slaked lime) was completely eroded after $30 \mathrm{~min}$. Plasters B (geopolymeric solution), C (enzymatic solution), and F (5\% plaster of Paris), after 5 min were eroded to an amount similar to that of earth-only plaster. Performances of sample $C$ were worse than the ones of the plaster without additives.

The results of the drilling resistance tests are shown in Figure $12 \mathrm{~B}$ as mean values in the depth ranges $0-10 \mathrm{~mm}, 0-2 \mathrm{~mm}$, and $2-10 \mathrm{~mm}$, and in Figure 8 as average curves for all the plasters. The data of Table 5 show that plasters $D$ and $E$ are very heterogeneous with an average standard deviation of $1.50 \mathrm{~N}$, but together with plaster $\mathrm{F}$, they show a higher resistance for the plaster without any stabiliser.

Table 5. Mean values of the drilling resistance measurements on earthen plaster mixtures.

\begin{tabular}{cccc}
\hline \multirow{2}{*}{ Sample ID } & \multicolumn{3}{c}{ Drilling Resistance (N) } \\
\cline { 2 - 4 } & $\begin{array}{c}\text { Depth Range (mm) } \\
\mathbf{0 - 1 0}\end{array}$ & $\begin{array}{c}\text { Depth Range (mm) } \\
\mathbf{0 - 2}\end{array}$ & $\begin{array}{c}\text { Depth Range (mm) } \\
\mathbf{2 - 1 0}\end{array}$ \\
\hline Earth & $1.40 \pm 0.71$ & $1.11 \pm 0.37$ & $1.47 \pm 0.72$ \\
\hline A & $1.04 \pm 0.24$ & $1.08 \pm 0.30$ & $1.02 \pm 0.19$ \\
\hline C & $1.22 \pm 0.34$ & $1.31 \pm 0.34$ & $1.20 \pm 0.30$ \\
\hline D & $1.86 \pm 1.28$ & $1.45 \pm 0.93$ & $1.95 \pm 1.30$ \\
\hline E & $2.66 \pm 1.68$ & $2.37 \pm 0.76$ & $2.74 \pm 1.72$ \\
\hline F & $1.79 \pm 0.80$ & $1.75 \pm 0.61$ & $1.80 \pm 0.77$ \\
\hline
\end{tabular}

$\mathbf{A}=$ earth + slaked lime; $\mathbf{C}=$ earth + enzymatic solution; $\mathbf{D}=$ earth + cement kiln dust; $\mathbf{E}=$ earth $+20 \%$ plaster of Paris; $\mathbf{F}=$ earth $+5 \%$ plaster of Paris. Note: sample B (geopolymeric solution) was not tested because the samples broke when closing the sample holder.

Figure 12B confirms the result for plaster E, the drilling resistance is higher than that of the earth-only plaster, throughout the whole range of hole depth. Plasters D and F also have a similar trend although it is less pronounced than plaster E. For the other additives, no increase in cohesion was observed for the non-stabilized plaster.

The results of the water absorption test are shown in Figure $12 \mathrm{C}$. The values obtained show that:

- $\quad$ plasters earth + slaked lime, earth + geopolymeric solution, and earth + enzymatic solutions display an absorption capacity a little higher or comparable with that of the earth-only plaster;

- $\quad$ plasters earth + cement kiln dust, earth $+20 \%$ plaster of Paris, and earth $+5 \%$ plaster of Paris, have a lower water absorption capacity.

In Table 6 , the mean value of the $\mu$ parameter calculated according to the results of the water vapor permeability and its variation $\Delta \mu(\%)$ are reported. The data referred to the tests of the individual layers show higher values for the fine fraction than for the coarse one. These values do not differ much between them (around 7-8\% of difference). The data show that only two additives (CKD and 20\% plaster of Paris) induce an appreciable variation of the parameter $\mu$ that is respectively $57 \%$ and $16 \%$. The other plasters show a little variation of $\mu$ or almost unchanged value compared to the earth-only plaster, $\Delta \mu$ (\%) below $10 \%$. Plaster with the enzymatic solution is close to the threshold of $\Delta \mu(\%)$ acceptability. 
Table 6. Water vapor permeability test results on earthen plaster mixtures: water vapor diffusion resistance coefficient and $\Delta \mu(\%)$

\begin{tabular}{|c|c|c|c|c|c|c|}
\hline \multirow[b]{2}{*}{ Sample ID } & \multicolumn{2}{|c|}{ Two Layers Sample } & \multicolumn{2}{|c|}{ Fine Layer Sample } & \multicolumn{2}{|c|}{ Coarse Layer Sample } \\
\hline & $\begin{array}{c}\mu \\
(-)\end{array}$ & $\begin{array}{c}\Delta \mu \\
(\%)\end{array}$ & $\begin{array}{c}\mu \\
(-)\end{array}$ & $\begin{array}{c}\Delta \mu \\
(\%)\end{array}$ & $\begin{array}{c}\mu \\
(-)\end{array}$ & $\begin{array}{c}\Delta \mu \\
(\%)\end{array}$ \\
\hline Earth & $8.0 \pm 0.2$ & - & $8.2 \pm 0.2$ & - & $7.6 \pm 0.1$ & - \\
\hline A & $8.6 \pm 0.1$ & 8.0 & $8.8 \pm 0.2$ & 8.0 & $8.2 \pm 0.1$ & 8.0 \\
\hline B & $8.0 \pm 0.1$ & 0 & $8.1 \pm 0.1$ & 1.0 & $7.7 \pm 0.1$ & 2.0 \\
\hline $\mathrm{C}$ & $8.8 \pm 0.1$ & 11.0 & $9.0 \pm 0.2$ & 11.0 & $8.4 \pm 0.2$ & 11.0 \\
\hline D & $12.5 \pm 0.2$ & 57.0 & $12.8 \pm 0.2$ & 57.0 & $11.9 \pm 0.2$ & 57.0 \\
\hline E & $9.2 \pm 0.2$ & 16.0 & $9.5 \pm 0.1$ & 16.0 & $8.8 \pm 0.1$ & 16.0 \\
\hline $\mathbf{F}$ & $8.2 \pm 0.1$ & 3.0 & $8.4 \pm 0.1$ & 3.0 & $7.8 \pm 0.2$ & 3.0 \\
\hline
\end{tabular}

$\boldsymbol{\mu}=$ water vapour diffusion resistance; $\mathbf{A}=$ earth + slaked lime; $\mathbf{B}=$ earth + geopolymeric solution; $\mathbf{C}=$ earth + enzymatic solution; $\mathbf{D}=$ earth + cement kiln dust; $\mathbf{E}=$ earth $+20 \%$ plaster of Paris; $\mathbf{F}=$ earth $+5 \%$ plaster of Paris.

The results of the colorimetric measurements are reported in Table 7 as the average values of the coordinates $\mathrm{L}^{*}, \mathrm{a}^{*}$, and $\mathrm{b}^{*}$, and the differences $\left(\Delta \mathrm{L}^{*}, \Delta \mathrm{a}^{*}, \Delta \mathrm{b}^{*}\right)$ of these values between stabilized plasters (A, B, C, D, E, F) and non-stabilized plaster. In addition, the $\Delta \mathrm{E}^{*}$ parameter is reported.

Table 7. Color measurements results on earthen plaster mixtures

\begin{tabular}{cccccccc}
\hline $\begin{array}{c}\text { Sample } \\
\text { ID }\end{array}$ & $\mathbf{L}^{*}$ & $\mathbf{a}^{*}$ & $\mathbf{b}^{*}$ & $\mathbf{\Delta} \mathbf{L}^{*}$ & $\mathbf{\Delta} \mathbf{a}^{*}$ & $\mathbf{\Delta} \mathbf{b}^{*}$ & $\boldsymbol{\Delta} \mathbf{E}^{*}$ \\
\hline Earth & $51.68 \pm 0.36$ & $8.04 \pm 0.06$ & $23.04 \pm 0.17$ & - & - & - & - \\
A & $72.70 \pm 0.21$ & $4.97 \pm 0.04$ & $19.89 \pm 0.15$ & 21.01 & -3.07 & -3.15 & 21.47 \\
B & $42.19 \pm 4.01$ & $5.89 \pm 0.12$ & $17.72 \pm 0.98$ & -9.49 & -2.16 & -5.32 & 11.09 \\
C & $48.37 \pm 0.15$ & $7.67 \pm 0.02$ & $21.78 \pm 0.05$ & -3.31 & -0.37 & -1.26 & 3.57 \\
D & $69.38 \pm 3.27$ & $5.13 \pm 0.54$ & $17.62 \pm 0.60$ & 17.69 & -2.91 & -5.42 & 18.73 \\
E & $64.97 \pm 0.84$ & $6.48 \pm 0.22$ & $21.35 \pm 0.48$ & 13.29 & -1.56 & -1.69 & 13.49 \\
F & $55.20 \pm 0.59$ & $7.64 \pm 0.17$ & $22.71 \pm 0.26$ & 3.51 & -0.40 & -0.33 & 3.55
\end{tabular}

A = earth + slaked lime; B = earth + geopolymeric solution; C = earth + enzymatic solution; $\mathbf{D}=$ earth + cement kiln dust; $E=$ earth $+20 \%$ plaster of Paris; $F=$ earth $+5 \%$ plaster of Paris.

Table 7 shows that plasters $\mathrm{A}, \mathrm{B}, \mathrm{D}$, and $\mathrm{E}$ changed with $\Delta \mathrm{E}^{*}$ values greater than 10 (human eye detection limit is 3). In particular, plaster $B$ shows a decrease of $L^{*}$ (darkening of the plaster surface) while others show an increase of this parameter resulting in a surface whitening. All the samples exhibit a decrease in $\mathrm{a}^{*}$ and $\mathrm{b}^{*}$ coordinates, more pronounced for $b^{*}$ which leads to a lower saturation of red and yellow components, and a consequent colder brown shade; plasters $\mathrm{F}$ and $\mathrm{C}$ do not seem to have changed their color with a $\Delta \mathrm{E}^{*}$ lower than 3.

The results of the tests (color and weight change measurements) assessing the response of plasters to the artificial ageing (thermo-hygrometric cycles) are shown in Table 8.

The artificial ageing caused evident changes in the color of plasters $\mathrm{C}, \mathrm{D}$, and $\mathrm{E}$ $\left(\Delta \mathrm{E}^{*}>3\right)$, even if also the earth-only plaster shows $\Delta \mathrm{E}^{*}$ very close to the detection limit of the human eye (=3). $\Delta \mathrm{E}^{*}$ of $\mathrm{A}, \mathrm{B}$, and F plasters is below this limit. The weight loss (as a percentage of the stabilized plaster and the non-stabilized one) is very low and similar for all the samples and it agrees with the loss of material due to the manipulation of the samples during the measurements. This means that accelerated ageing is not strong enough (both for the number of cycles and for the thermo-hygrometric stress of the cycle) to affect the cohesion of the materials. 
Table 8. Colorimetric and weight measurements after thermo-hygrometric cycles.

\begin{tabular}{cccccc}
\hline & \multicolumn{3}{c}{ Colorimetric Measurements } & $\begin{array}{c}\text { Weight } \\
\text { Measurements }\end{array}$ \\
\cline { 2 - 6 } & $\boldsymbol{\Delta} \mathbf{L}^{*}$ & $\boldsymbol{\Delta} \mathbf{a}^{*}$ & $\boldsymbol{\Delta} \mathbf{b}^{*}$ & $\boldsymbol{\Delta} \mathbf{E}^{*}$ & $\begin{array}{c}\text { \# Weight } \\
\text { Loss(\%) }\end{array}$ \\
\hline Earth & 2.81 & -0.70 & -0.36 & 2.92 & $0.29 \pm 0.10$ \\
A & -1.82 & 0.47 & 0.32 & 1.91 & $0.30 \pm 0.10$ \\
B & 2.05 & 0.36 & 0.23 & 2.09 & $0.33 \pm 0.10$ \\
C & 3.78 & -0.08 & 1.21 & 3.97 & $0.20 \pm 0.10$ \\
$\mathbf{D}$ & 4.24 & 0.11 & 3.03 & 5.22 & $0.32 \pm 0.10$ \\
E & 3.79 & -0.30 & 0.39 & 3.82 & $0.24 \pm 0.10$ \\
F & 1.69 & -0.76 & -1.57 & 2.43 & $0.25 \pm 0.10$ \\
\hline
\end{tabular}

A = earth + slaked lime; B = earth + geopolymeric solution; C = earth + enzymatic solution; D = earth + cement kiln dust; $\mathbf{E}=$ earth $+20 \%$ plaster of Paris; $\mathbf{F}=$ earth $+5 \%$ plaster of Paris; ${ }^{\#}$ Weight loss $(\%)=\left[\left(\right.\right.$ weight $_{\text {before aging }}$ - weight $\left.{ }_{\text {after aging }}\right) /$ weight before aging $]^{*} 100$.

\section{Discussion}

\section{Performances of the Plasters}

The performances of the plasters with the various additives suggest the following considerations.

As for the effectiveness of the additives in increasing the resistance to the erosive action of water and drilling, the best results for both tests are obtained by earth + plaster of Paris (in both concentrations) and earth + CKD plasters; while for the other additives, there is a slight improvement in these performances (earth + slaked lime) or similar behaviors (earth + enzymatic solution) or sometimes a slight deterioration (earth + geopolymer solution) when compared to the non-stabilized plaster.

In the case of earth + plaster of Paris, the increase in resistance is due to the binding action of gypsum which is formed thanks to the hydration of the plaster of Paris. As the amount of plaster of Paris increase, there is an increase of the plaster resistance.

In the case of CKD, the binding/reinforcing action is partially due to both the formation of calcite thanks to the hydration and subsequent carbonation of the calcium oxide, and pozzolanic reaction compounds as identified in the XRD analysis of the clay fraction. Concerning the action of these compounds, there are conflicting opinions, in fact once established that the formation of crystalline phases such as cement compounds (CSH like tobermorite) [91] have a binding action and increase the mechanical strength of the material, there is no agreement whether the crystalline zeolitic phases can determine an increase in mechanical strength [92] or disintegration of the matrix of the material [92]. In this regard, however, Ma et al. [92] attribute the lower mechanical performances to the formation of a porous and loosened microstructure formed in the matrix rather than to the formation of crystalline zeolitic phases with disaggregating power [93]. The latter phenomenon may have occurred in the case of earth + geopolymer solution in which the water resistance was slightly worse than that of the plaster made only of earth and the drilling resistance test could not be carried out due to the disintegration of the specimen in the closure of the sample holder.

As for the earth + slaked lime, where the cementing/reinforcing action is linked to the double process of formation of calcite and products of the pozzolanic reaction, a mild increase in the resistance to the action of the water and drilling has been obtained. This datum agrees with literature data showing that hydrated lime would lead to stabilized earth performance slightly lower than that of earth stabilized with quicklime (present in the CKD) [91]. This result would be consistent with what has been observed on the effectiveness of the alkaline environment in promoting the attack of the clay minerals, probably linked to the exothermicity of the reaction between $\mathrm{CaO}$ and water [94]. 
As for the earth + enzymatic solution, no increase in resistance has been observed. Muguda and Nagaraj [57] reported that the curing conditions influence the increase in resistance.

In particular, Muguda and Nagaraj [57] used sealed curing and one in which water was continuously supplied and they observed that after 60 days, the samples cured with the first method had a much higher resistance than those cured with the second method. Therefore, it could be possible that the cured conditions adopted in the experimentation (namely to sprinkle with deionized water for one time daily (about $0.1 \mathrm{~L} / \mathrm{m}^{2}$ ), in the same time, for 45 days), have not favored the increase in the mechanical performances of the plaster.

As for the effectiveness of the additives in delaying / decrease the entry of liquid water, the results are similar to those observed for the increase in resistance toward the mechanical action of water and toward drilling. This behavior could be related to a decrease in the water uptake (Karsten pipe test), and consequently, in the porosity accessible to water due to the following phenomena:

- in the case of the addition of plaster of Paris, a compact and slightly porous material is obtained with the minimum amount of water required for hydration. This is because the hydration of plaster of Paris occurs with an increase in volume [50]. The greater the amount of plaster of Paris added to the earth, the more evident the effect obtained. This would confirm what was exposed above;

- in the case of CKD and slaked lime, calcite and new calcium silicates phases are formed which would fill the pores by decreasing the porosity involved in the passage of water in the liquid form (capillary porosity and macroporosity) in favor of the micropores in which the passage of water occurs in the vapor phase [91,95].

The negative result in the absorption test occurred for the sample earth + geopolymer solution is to be attributed to the formation of a porous and loosened microstructure in the matrix as indicated by Ma et al. (2012) [92] rather than to the formation of crystalline zeolitic phases that would disaggregate the matrix as suggested by Grutzeck et al. [93]. This effect is not evident in the plaster of earth + CKD and earth + slaked lime where these phases have also been identified.

The plaster earth + enzymatic solution did not show any variation in the water absorption test although, as reported in the literature, the presence of this additive should contribute to decreasing the permeability to water [54,57]. This product may be not suitable for the type of earth used in this work. Surely the lack of knowledge of the composition of this solution does not help in the interpretation of its failure to improve the characteristics of the earth [95]. Maybe the percentage to be used, indicated in the technical data sheet, was too low as observed by some authors using the same product $[57,94]$.

As for the changes induced by the various additives in water vapor permeability, they are also following what has been observed for the increase in resistance and the decrease in the absorption of water in liquid form.

In particular, when compared to non-stabilized plaster, the one earth + CKD and earth $+20 \%$ plaster of Paris show a variation in the resistance to the transmission of water vapor extremely high in the first case (57\%) and high in the second one (16\%). This increase in the resistance to water vapor transmission is attributable to the increase in small pores [95] which are affected by condensation/transport of water vapor $[60,96-98]$ to the detriment of those affected by phenomena of liquid water transport. For both plasters, the increase in small pores, as mentioned, seems to be due to the formation of the new phases which have given rise to a more compact structure with respect to that of the earth-only plaster. The data obtained with the plaster stabilized with CKD is of concern because such a significant increase in the resistance to water vapor transmission could significantly influence the behavior of the plaster when combined with the material that supports it, favoring over time the formation of interstitial condensation and subsequent decay [65].

Concerning the earth $+5 \%$ plaster of Paris, earth + slaked lime, earth + geopolymeric solution plasters, an acceptable if not unchanged variation in the resistance to water vapor 
transmission is observed. This behavior, as for the plasters stabilized with CKD and 20\% plaster of Paris, must be attributed to the formation of the new phases that form inside the larger pores.

As for the plaster earth + the enzymatic solution, the increase in resistance to the transmission of water vapor is at the limit of a hypothetical acceptance threshold (10\%) [73]. It is not clear the reason for this variation since in all the previous tests this plaster showed a behavior similar to that of the earth-only plaster. A possible explanation is a too low percentage of the enzymatic solution, not capable to induce any change in earth characteristics $[40,57]$.

As regards the color changes with respect to the non-stabilized plaster, those made of earth + slaked lime, earth + geopolymer solution, earth + CKD, and earth $+20 \%$ plaster of Paris showed the greatest variations $\left(\Delta \mathrm{E}^{*}>10\right.$ respect to a human eyes detection limit of $\Delta \mathrm{E}^{*}$ equal to 3 ). Consistent with the color of the additives and their corresponding compounds after setting (lime and plaster), the plasters of earth + slaked lime, earth + CKD, and earth $+20 \%$ plaster of Paris showed a whitening. On the contrary, the plaster earth + geopolymeric solution showed a darkening. The plasters earth + enzymatic solution and earth $+5 \%$ plaster of Paris showed only a slight variation.

All the samples exhibit a decrease in $a^{*}$ and $b^{*}$ coordinates, more pronounced for $b^{*}$ which leads to a lower saturation of red and yellow components, and a consequent colder brown shade.

The ageing tests did not show particular changes both in color and in the loss of material from the specimens, highlighting that probably the accelerated ageing is not strong enough (both for the number of cycles and for the thermo-hygrometric stress of the cycle) to induce an appreciable change in the specimens.

\section{Conclusions}

The research of solutions able to increase the durability of the earthen plasters, applied on earthen architecture through the use of stabilizers with sustainability characteristics, is one of the challenges that must be faced to make these materials even more "green". The decreased maintenance interventions and, consequently, the related costs would give local administrations the possibility of more extensive interventions on this type of architecture, often neglected and at risk, fostering its preservation over time. The additives studied in the present work, aimed at increasing the durability of earthen plasters, and selected based on low environmental impact principles (energy costs and emission of pollutants during production, availability on-site), have shown interesting results, particularly for the gypsum stabilizer. The gypsum binder, although being a salt, does not cause any decay phenomena. It is formed by hydration of the corresponding hemihydrate $\left(\mathrm{CaSO}_{4} \cdot 0.5 \mathrm{H}_{2} \mathrm{O}\right)$, during the setting/hardening process and not by reaction of the calcite with acid rains or at the expense of other constituents of the primary material, as it happens for example in the wellknown phenomenon that leads to the formation of the black crusts [99-102]. The gypsum is not the result of a secondary sulfation reaction (such as ettringite) which is considered potentially harmful to concrete only if it is formed in the hardened material and not during the setting as in the case of the aluminous cement [103]. Once the gypsum has hardened, it does not dry out easily (temperatures close to $120^{\circ} \mathrm{C}$ are required) and is poorly soluble (Henry and Stewart, 2012), a more stable behavior in environmental conditions could be achieved by the addition of a little \% of lime (about $2.5 \%$ ) as traditionally done in the alker technology [104,105]. Although CKD proved to be the best in terms of resistance to erosion, drilling resistance, waterproofing, and action against swelling clay minerals, therefore making the plaster more resistant toward imbibition and drying cycles, this additive is not compatible in terms of permeability to water vapor, which is excessively reduced. Therefore, the material can be affected by condensation phenomena both between the plaster and the substrate and among the different plaster layers, with dangerous consequences. Lime could have been a valid alternative for the capability to react with the swelling clay minerals passivating their surface and giving rise to pozzolanic reaction products. Unfortunately, it 
did not produce significant results in increasing the performances of the plaster. Further experimentation with a higher amount of product (8-10\%) would be necessary. For a complete understanding of the adequacy of these materials, they will be subjected to further tests, directly on-site, to check their compatibility with the earthen masonries (adhesion, shrinkage, etc.), and their effective resistance to weathering (behavior over time in the external environment).

Supplementary Materials: The following are available online at https:/ /www.mdpi.com/2071-105 0/13/3/1090/s1, Appendix part A and Appendix part B.

Author Contributions: Please note that all authors of this paper should be considered as principal authors. The concept of the research has been shared by all authors. All the authors have worked to find the raw materials and for the realization of the earthen plasters. M.M. has measured the particle size distribution of the earth and has performed water erosion and absorption tests. F.F. has carried out the XRD analysis of the clay fraction of the earth before and after the addition of the stabilisers. S.R. carried out XRD analyses of raw materials and stabilized plasters, TG analysis, DRMS measurements, water vapor permeability test and thermo-hygrometric cycles. L.L. has carried out $\mathrm{XRF}$ and colorimetric analyses. All the authors contributed to the discussion of the results and the drafting of the article. All authors have read and agreed to the published version of the manuscript.

Funding: This research received no external funding.

Institutional Review Board Statement: Not applicable.

Informed Consent Statement: Not applicable.

Data Availability Statement: Not applicable.

Conflicts of Interest: The authors declare that the research was conducted in the absence of any commercial or financial relationships that could be construed as a potential conflict of interest.

\section{References}

1. Conti, G. Antologia della terra cruda 1997-2004. In Viaggio Nella Terra Cruda in Italia; Casa Editrice Tinari: Villamagna, Italy, 2004.

2. Bollini, G. Terra Cruda tra Tradizione e Innovazione; Edicom Edizioni: Manzano, Italy, 2008.

3. Available online: https://whc.unesco.org/en/earthen-architecture/ (accessed on 10 December 2020).

4. Houben, H.; Guillaud, H. Traité de Construction en Terre; Editions Parenthèses: Marseille, France, 1989.

5. Houben, H.; Guillaud, H. Earth Construction: A Comprehensive Guide; Intermediate Technology Publication: London, UK, 1994.

6. Warren, J. Conservation of Earth Structures; Butterworth-Heinemann: Oxford, UK, 1999.

7. Scudo, G.; Narici, B.; Talamo, C. Costruire con la Terra; Esselibri: Napoli, Italy, 2001.

8. Jaquin, P.; Augarde, C. Earth Building. History, Science and Conservation; IHS brepress: Bracknell, UK, 2012.

9. Bertagnin, M.; Achenza, M.; Munciguerra, C. Architetture di terra in Italia. In Tipologie, Tecnologie e Culture Costruttive; Edicom Edizioni: Monfalcone, Italy, 1999.

10. Guillaud, H. A global challenge: Preserving earthen architecture. World Herit. 2008, 48, 4-15.

11. Sabbadini, S. Intonaci e finiture in terra. In Scritti Sulla Terra; Galdieri, E., Ed.; Il Prato edizioni: Saonara, Italy, $2010 ;$ pp. 56-68.

12. Svoboda, P.; Prochazka, P. Outdoor earthen plasters. Organ. Technol. Manag. Constr. An Int. J. 2012, 4, 420-423. [CrossRef]

13. McGregor, F.; Heath, A.; Shea, A.; Lawrence, M. The moisture buffering capacity of unfired clay masonry. Build. Environ. 2012, 82, 599-607. [CrossRef]

14. Stazi, F.; Nacci, A.; Tittarelli, F.; Pasqualini, E.; Munafò, P. An experimental study on earthen plasters for earthen building protection: The effect of different admixtures and surface treatments. J. Cult. Herit. 2016, 17, 27-41. [CrossRef]

15. Taylor, M.R. An evaluation of the New Mexico State monuments test walls at Fort Selden. In Proceedings of the Adobe 90, Las Cruces, NM, USA, 14-19 October 1990; Getty Institute: Los Angeles, CA, USA, 1990; pp. 383-389.

16. Uviña Contreras, F.; Guerrero Baca, L. El uso de la cal en la conservación de estructuras de tierra. In Proceedings of the Fourth International Adobe Conference of the Adobe Association of the Southwest, El Rito, NM, USA, 18-20 May 2007; Mithchel, T., Ed.; El Rito Campus of NNMC: El Rito, NM, USA, 2007; pp. 40-45.

17. Guerrero, B.L. Revestimientos. In Tècnicas de Construcción con Tierra; Neves, C., Obede Borges, F., Eds.; FEB-UNESP/PROTERRA: Bauru, Brazil, 2011; pp. 72-77.

18. Choobbasti, A.J.; Ghodrat, H.; Vahdatirad, M.J.; Firouzian, S.; Barari, A.; Torabi, M.; Bagherian, A. Influence of using rice husk ash in soil stabilization method with lime. Front. Earth Sci. China 2010, 4, 471-480. [CrossRef]

19. Gomes, M.I.; Gonçalves, T.D.; Faria, P. Hydric Behaviour of Earth Materials and the Effects of Their Stabilization with Cement or Lime: Study on Repair Mortars for Historical Rammed Earth Structures. J. Mater. Civ. Eng. 2016, 28, 04016041. [CrossRef] 
20. Ciancio, D.; Beckett, C.T.S.; Carraro, J.A.H. Optimum lime content identification for lime-stabilised rammed earth. Constr. Build. Mater. 2014, 53, 59-65. [CrossRef]

21. Eires, R.; Camões, A.; Jalali, S. Ancient Materials and Techniques to Improve the Earthen Building Durability. Key Eng. Mater. 2014, 634, 357-366. [CrossRef]

22. Mattone, R.; Pasero, G.; Rivotti, A.; Tosco, V. Uso de productos naturals para mejorar el comportamiento al agua de revoques à base de tierra. In Proceedings of the IV seminario Ibero-americano de Construccion de Tierra, Monsaraz, Portugal, 7-12 October 2005; Jorge, F., Ed.; Argumentum: Lisbon, Portugal, 2005; pp. 266-269.

23. Rivotti, A.; Tosco, V. Intonaci di terra e gesso. Il Progett. Sostenibile 2006, 12, 62-67.

24. Mattone, M.; Ibnoussina, M.; Rescic, S.; Fratini, F.; Magrini, D.; Mecchi, A.M.; Nocairi, M. Stabilization of earthen plasters: Exchange of knowledge and experiences between Italy and Morocco. J. Mater. Environ. Sci. 2016, 7, 3647-3655.

25. Elert, K.; Sebastián, E.; Valverde, I.; Rodriguez-Navarro, C. Alkaline treatment of clay minerals from the Alhambra Formation: Implications for the conservation of earthen architecture. Appl. Clay Sci. 2008, 39, 122-132. [CrossRef]

26. Elert, K.; Pardo, E.S.; Rodriguez-Navarro, C. Alkaline activation as an alternative method for the consolidation of earthen architecture. J. Cult. Herit. 2015, 16, 461-469. [CrossRef]

27. Elert, K.; Bel-Anzué, P.; Monasterio-Guillot, L.; Pardo, S. Performance of alkaline activation for the consolidation of earthen architecture. J. Cult. Herit. 2019, 39, 93-102. [CrossRef]

28. Kita, Y. The functions of vegetable mucilage in lime and earth mortars-A review. In Proceedings of the HMC2013-3rd Historic Mortars Conference, Glasgow, UK, 11-13 September 2013; pp. 1-6.

29. Laborel-Préneron, A.; Aubert, J.E.; Magniont, C.; Tribout, C.; Bertron, A. Plant aggregates and fibres in earth construction materials: A review. Constr. Build. Mater. 2016, 111, 719-734. [CrossRef]

30. Van Damme, H.; Houben, H. Earth concrete. Stabilization revisited. Cem. Concr. Res. 2018, 114, 90-102. [CrossRef]

31. Vissac, A.; Bourgès, A.; Gandreau, D.; Anger, R.; Fontaine, L. Argiles \& Biopolymères les Stabilisants Naturels Pour la Construction en Terre; CRAterre Editions: Villefontaine, France, 2017.

32. Vissac, A.; Fontaine, L.; Anger, R. Description des molécules des stabilisants organiques \& Description de la nature des interactions physico chimiques entres ces molécules naturelles et les argiles. In 'Project PaTerre+' Interactions Argiles/Biopolymères: Patrimoine Architectural en Terre; CRAterre Éditions: Villefontaine, France, 2013.

33. Rodriguez-Navarro, C.; Ruiz-Agudo, E.; Burgos-Cara, A.; Elert, K.; Hansen, E.F. Crystallization and Colloidal Stabilization of $\mathrm{Ca}(\mathrm{OH})_{2}$ in the Presence of Nopal Juice (Opuntia ficus Indica): Implications in Architectural Heritage Conservation. Langmuir 2017, 33, 10936-10950. [CrossRef]

34. Mattone, M.; Rescic, S.; Fratini, F.; Manganelli Del Fa, R. Experimentation of Earth-Gypsum Plasters for the Conservation of Earthen Constructions. Int. J. Archit. Herit. 2017, 11, 763-772. [CrossRef]

35. Schroeder, H. Sustainable Building with Earth; Springer: Cham, Switzerland, 2016. [CrossRef]

36. Gomes, M.I.; Faria, P.; Goncalves, T.D. Earth-based mortars for repair and protection of rammed earth walls. Stabilization with mineral binders and fiber. J. Clean. Prod. 2018, 172, 2401-2414. [CrossRef]

37. Izaguirre, A.; Lanas, J.; Álvarez, J.I. Behaviour of a starch as a viscosity modifier for aerial lime-based mortars. Carbohydr. Polym. 2010, 80, 222-228. [CrossRef]

38. Cardenas, A.; Argüelles-Monal, W.; Goycoolea, F. On the Possible Role of Opuntia ficus-indica Mucilage in Lime Mortar Performance in the Protection of Historical Buildings. J. Prof. Assoc. Cactus Dev. 1998, 3, 64-71.

39. Stafford, H.; Bee, R. Building with Lime and Lime Stabilized Soil: A Manual and Practical Guide for the Selection, Preparation, Testing and Application of Natural Materials for Durable Earth-Based Low-Cost Construction, 2nd ed.; International Organization for Migration Publication: Grand-Saconnex, Switzerland, 2015.

40. Thomas, A.G.; Rangaswamy, B.K. Strength behaviour of enzymatic cement treated clay. Int. J. Geotech. Eng. 2019, 1-14. [CrossRef]

41. Hardjito, D.; Fung, S.S. Fly Ash-Based Geopolymer Mortar Incorporating Bottom Ash. Mod. Appl. Sci. 2010, 4, 44-52. [CrossRef]

42. Standards New Zealand (NZS) 4298-D 1998. Materials and Workmanship for Earth Buildings, Appendix D. Available online: https:/ / www.standards.govt.nz/sponsored-standards/building-standards/nzs4298/ (accessed on 15 January 2020).

43. Standards New Zealand (NZS) 4298-E 1998. Materials and Workmanship for Earth Buildings, Appendix E. Available online: https: / / www.standards.govt.nz/sponsored-standards/building-standards/nzs4298/ (accessed on 15 January 2020).

44. Karsten, R. Bauchemie für Studium und Praxis; Heidelberg, Germany, 1983.

45. Hendrickx, R. Using the Karsten tube to estimate water transport parameters of porous building materials. Mater. Struct. 2013, 46, 1309-1320. [CrossRef]

46. EN 15803 2010. Conservation of Cultural Property-Test Methods—Determination of Water Vapour Permeability ( $\delta p)$. Available online: http:/ / store.uni.com/catalogo/uni-en-15803-2010?josso_back_to=http:/ / store.uni.com/josso-security-check.php\& josso_cmd=login_optional\&josso_partnerapp_host=store.uni.com (accessed on 15 January 2020).

47. EN 15886 2010. Conservation of Cultural Property-Test Method-Colour Measurements of Surfaces. Available online: http:/ / store.uni.com/catalogo/uni-en-15803-2010?josso_back_to=http:/ / store.uni.com/josso-security-check.php\&josso_ cmd=login_optional\&josso_partnerapp_host=store.uni.com (accessed on 15 January 2020).

48. Avrami, E.; Guillaud, H.; Hardy, M. (Eds.) Terra Literature Review; The Getty Conservation Institute: Los Angeles, CA, USA, 2008.

49. Isik, B.; Tulbentci, T. Sustainable Housing in island conditions using Alker-Gypsum-stabilized earth: A case study from Northern Cyprus. Build. Environ. 2008, 43, 1426-1432. [CrossRef] 
50. Chatterajin, S.; Jefery, D.J.W. Volume expansion of setting plaster. Trans. Faraday Soc. 1964, 60, 1947-1950. [CrossRef]

51. Falchi, L.; Fratini, F.; Rescic, S.; Pirolandi, L.; Ricci, G.; Zendri, E. From the historical sugar refinery of Chichaoua (Morocco) to the lab: Reverse engineering experimentation on the hydration of earthen materials stabilized with lime. J. Mater. Environ. Sci. 2016, 7, 3595-3604.

52. Davidovits, J. Geopolymers: Inorganic Polymeric New Materials. J. Therm. Anal. Calorim. 1991, 37, 1633-1656. [CrossRef]

53. Mubarak, Y.A.; Al-Swalkah, A.I.; Sweis, F.K. The Effect of Alkaline Additives on the Operating Conditions of Kaolinitic Polymerization. Jordan J. Mech. Ind. Eng. 2011, 5, 389-401.

54. Taha, M.R.; Khan, T.A.; Taha Jawad, I.; Akbar Firoozi, A.; Asghar Firoozi, A. Recent experimental studies in soil stabilization with bio-enzymes-a review. Electron. J. Geotech. Eng. 2013, 18, 3881-3894.

55. Scholen, D.E. Non-Standard Stabilizers; Report FHWA-FLP-92-011; FHWA, U.S. Department of Transportation: Atlanta, GA, USA, 1992.

56. Rauch, A.F.; Katz, L.; Liljestrand, H. An Analysis of the Mechanisms and Efficacy of Three Liquid Chemical Soil Stabilizers Research Project 7-1993 Evaluation of Nontraditional Soil and Aggregate Stabilizers Conducted for the Texas Department of Transportation in cooperation with the U.S. Department of Transportation Federal Highway Administration by the Center for Transportation Research Bureau of Engineering Research the University of Texas at Austin; University of Texas: Austin, TX, USA, 2003.

57. Muguda, S.; Nagaraj, H.B. Effect of enzymes on plasticity and strength characteristics of earthen construction material. GeoEngineering 2019, 10, 2-14. [CrossRef]

58. Peethamparan, S.; Olek, J.; Diamond, S. Physicochemical Behaviour of Cement Kiln Dust-Treated Kaolinite Clay. Transp. Res. Rec. 2008, 2059, 80-88. [CrossRef]

59. Peethamparan, S.; Olek, J.; Diamond, S. Mechanism of stabilization of Na-montmorillonite clay with cement kiln dust. Cem. Concr. Res. 2009, 39, 580-589. [CrossRef]

60. Ismaiel, H.A.H. Cement Kiln Dust Chemical Stabilization of Expansive Soil Exposed at El-Kawther Quarter, Sohag Region. Egypt Int. J. Geosci. 2013, 4, 1416-1424. [CrossRef]

61. ASTM D2217-85. Standard Practice for Wet Preparation of Soil Samples for Particle-Size Analysis and Determination of Soil Constants. 1998. Available online: https:/ / www.astm.org/Standards/D2217.htm (accessed on 15 March 2020).

62. ASTM D422-63. Standard Test Method for Particle-Size Analysis of Soils. 1990. Available online: https://www.astm.org/ Standards/D422 (accessed on 15 March 2020).

63. Cipriani, C. Ricerche sui minerali costituenti le arenarie: (I) Sulla composizione mineralogica della frazione argillosa di alcune arenarie Macigno. Atti Soc. Toscana Sci. Nat. 1958, 65, 86-106.

64. Franzini, M.; Leoni, L.; Saitta, M. Revisione di una metodologia analitica per fluorescenza-X, basata sulla correzione completa degli effetti di matrice. Rend. Soc. Ital. Mineral. Petrol. 1975, 31, 365-378.

65. Matthew, R.H.; Lindsay, R.; Krayenhoff, M. (Eds.) Modern Earth Buildings: Materials, Engineering, Constructions and Applications; Elsevier Science and Technology: Cambridge, UK, 2012.

66. Standards Association of Zimbabwe, (SAZS) 724. In Rammed Earth Structures; South African Development Community: Harare, Zimbabwe, 2001.

67. Standards Australia. In The Australian Earth Building Handbook; Standards Australia International Publisher: Sydney, Australia, 2002.

68. Papamichos, E.; Papanicolopolus, S.A.; Larsen, I.; Alnæ, L.; Rescic, S. Method for in situ, quasi non-destructive diagnosis of mechanical properties and damage of natural building stones. In Proceedings of the Gulf rock 2004, the 6th American Rock Mechanics Symposium (NARMS): Rock Mechanics Across Borders and Disciplines, Houston, TX, USA, 5-9 June 2004; pp. 4-583.

69. Valentini, E.; Benincasa, A.; Tiano, P.; Fratini, F.; Rescic, S. On-Site Drilling Resistance Profiles of Natural Stones. In Proceedings of the International Workshop in Situ Monitoring of Monumental Surfaces, Florence, Italy, 27-29 October 2008; Tiano, P., Pardini, C., Eds.; Edifir-Edizioni: Florence, Italy, 2008; pp. 195-204.

70. Rescic, S.; Fratini, F.; Tiano, P. Onsite evaluation of the mechanical properties of Maastricht limestone and their relationship with the physical characteristics. Geol. Soc. Lond. Spec. Publ. 2010, 331, 203-207. [CrossRef]

71. Lettieri, M.; Masieri, M. Performances and Coating Morphology of a Siloxane-Based Hydrophobic Product Applied in Different Concentrations on a Highly Porous Stone. Coatings 2016, 6, 60. [CrossRef]

72. Snehtlage, R. Stone conservation. In Stone in Architecture; Siegesmund, S., Snethlage, R., Eds.; Springer: Berlin/Heidelberg, Germany, 1994; pp. 517-520.

73. Delgado Rodrigues, J.; Grossi, A. Indicators and ratings for the compatibility assessment of conservation actions. J. Cult. Herit. 2007, 8, 32-43.

74. CIELAB Color Space; International Commission on Illumination (CIE): Wien, Austria, 1976.

75. ASTM D559/D559M. Standard Test Methods for Wetting and Drying Compacted Soil-Cement Mixtures. 2015. Available online: https:/ / www.astm.org/Standards/D558.htm (accessed on 15 March 2020).

76. ASTM D4141/D4141M. Standard Practice for Conducting Black Box and Solar Concentrating Exposures of Coatings. 2014. Available online: https: / / www.astm.org/Standard/alpha-lists/D.html (accessed on 15 March 2020).

77. ASTM D560/D560M. Standard Test Methods for Freezing and Thawing Compacted Soil-Cement Mixtures. 2015. Available online: https:/ / www.astm.org/DATABASE.CART/HISTORICAL/D560D560M-15.htm (accessed on 15 March 2020).

78. RILEM TC 176-IDC 2004. Internal damage of concrete due to frost action. In Final Recommendation Test Methods of Frost Resistance of Concrete: CIF-Test: Capillary Suction, Internal Damage and Freeze-Thaw Test-Reference Method and Alternative Methods A and B; RILEM Publications SARL: Paris, France, 2004. 
79. Aloiz, E.M. New Investigations into a Historic Treatment: The Efficacy of Gelatin as an Adhesive for Earthen Finishes at Mesa Verde National Park. Master Thesis, University of Pennsylvania, Philadelphia, PA, USA, 2011.

80. Gabrovšek, R.; Vuk, T.; Kaučič, V. Evaluation of the Hydration of Portland Cement Containing Various Carbonatesby Means of Thermal Analysis. Acta Chim. Slov. 2006, 53, 159-165.

81. Miller, S.A. Use of Diatomaceous Earth as a Siliceous Material in the Formation of Alkali Activated Fine-Aggregate Limestone Concrete. Master's Thesis, Drexel University, Philadelphia, PA, USA, 2011.

82. Fodvari, M. Handbook of Thermogravimetric System of Minerals and Its Use in Geological Practice; Geological Institute of Hungary: Budapest, Hungary, 2011.

83. Escalera, E.; Antti, M.L.; Odén, M. Thermal treatment and phase formation in kaolinite and illite based clays from tropical regions of Bolivia. IOP Conf. Ser. Mater. Sci. Eng. 2012, 31, 12-17. [CrossRef]

84. Shekhawat, M.S. Thermogravimetric and differential thermal analysis of clay of western Rajasthan (India). India Int. J. Mod. Phys. Conf. Ser. 2013, 22, 458-465. [CrossRef]

85. Soriano, L.; Tashima, M.M.; Bonilla, J.M.; Payá, J.; Monzó, J.; Borrachero, M.V. Use of high-resolution thermogravimetric analysis (HRTG) technique in spent FCC catalyst/Portland cement pastes. J. Therm. Anal Calorim. 2015, 120, 1511-1517. [CrossRef]

86. Collier, N.C. Transition and decomposition temperatures of cement phases- a collection of thermal analysis data. Ceram. Silikáty 2016, 60, 338-343. [CrossRef]

87. Guanyu, W.; Hejing, W.; Nan, Z. In situ high temperature X-ray diffraction study of illite. Appl. Clay Sci. 2017, 146, 254-263.

88. Marsh, A.; Heath, A.; Patureau, P.; Evernden, M.; Walker, P. Alkali activation behaviour of un-calcined montmorillonite and illite clay minerals. Appl. Clay Sci. 2018, 166, 250-261. [CrossRef]

89. Yanguang, C.; Shuli, C.; Qiqi, W.; Hongjing, H.; Jia, L.; Yue, K.; Wei, K.; Haiying, W.; Shuyu, H.; Hua, S.; et al. Optimization of crystal growth of sub-micron ZSM-5 zeolite prepared by using $\mathrm{Al}(\mathrm{OH})_{3}$ extracted from fly ash as an aluminum source. J. Hazard. Mater. 2018, 349, 18-26.

90. Liguori, B.; Aprea, P.; de Gennaro, B.; Iucolano, F.; Colella, A.; Caputo, D. Pozzolanic enzyme of Zeolites: The Role of Si/Al Ratio. Materials 2019, 12, 4231. [CrossRef]

91. Amadi, A.A.; Okeiyi, A. Use of quick and hydrated lime in the stabilization of lateritic soil: A comparative analysis of laboratory data. Geo-Eng. 2017, 8. [CrossRef]

92. Ma, Y.; Hu, J.; Ye, G. The effect of activating solution on the mechanical strength, reaction rate, mineralogy, and microstructure of alkali-activated fly ash. J. Mater. Sci. 2012, 47, 4568-4578. [CrossRef]

93. Grutzeck, M.W.; Kwan, S.; Di Cola, M. Zeolite formation in alkali-activated cementitious systems. Cem. Concr. Res. 2004, 34, 949-955. [CrossRef]

94. Müller, C.J. Pozzolanic Activity of Natural Clay Minerals with Respect to Environmental Geotechnics. Ph.D. Thesis, Swiss Federal Institute of Technology Zurich, Zurich, Switzerland, 2005.

95. Bourokba Mrabent, S.A.; Hachichi, A.; Souli, H.; Taibi, S. Effect of lime on some physical parameters of a natural expansive clay from Algeria. Eur. J. Environ. Civil. Eng. 2015, 21, 1-18. [CrossRef]

96. Barsottelli, M.; Fratini, F.; Giorgetti, G.; Manganelli Del Fà, C. Microfabric and alteration in the Carrara marble: A preliminary study. Sci. Technol. Cult. Herit. 1998, 7, 109-120.

97. Togkalidou, T.; Karoglou, M.; Bakolas, A.; Giakoumaki, A.; Moropoulou, A. Correlation of Water Vapor Permeability with microstructure characteristics of building materials using robust chemometrics. Transp. Porous. Med. 2013, 99, 273-295. [CrossRef]

98. Bourgès, A.; Tiennot, J.M.; Mertz, D.; Liégey, A.; Bouquillon, A. Review of earthen materials consolidation with ethyl silicate. In Proceedings of the XXIIth World Congress on Earthen Architecture, TERRA, Lyon, France, 11-14 July 2016 ; pp. 104-107.

99. Lewry, A.J.; Williamson, J. The setting of gypsum plaster. Part I the hydration of calcium sulphate hemihydrate. J. Mater. Sci. 1994, 29, 5279-5284. [CrossRef]

100. Lewry, A.J.; Williamson, J. The setting of gypsum plaster. Part II development of microstructure and strength. J. Mater. Sci. 1994, 29, 5524-5528. [CrossRef]

101. Karni, J.; Karni, E. Gypsum in construction: Origin and properties. Mater. Struct. 1995, 28, 92-100. [CrossRef]

102. Calparsoro, E.; Maguregui, M.; Giakoumaki, A.; Morillas, H.; Madariaga, J.M. Evaluation of black crust formation and soiling process on historical buildings from the Bilbao metropolitan area (north of Spain) using SEM-EDS and Raman microscopy. Environ. Sci. Pollut. Res. Int. 2017, 24, 9468-9480. [CrossRef]

103. Xu, L.; Wang, P.; Zhang, G. Formation of ettringite in Portland cement/calcium aluminate cement/calcium sulfate ternary system hydrates at lower temperatures. Constr. Build. Mater. 2012, 31, 347-352. [CrossRef]

104. Yilmaz, I.; Civelekoglu, B. Gypsum: An additive for stabilization of swelling clay soils. Appl. Clay Sci. 2009, 44, 166-172. [CrossRef]

105. Kiliç, R.; Küçükali, Ö.; Ulamis, K. Stabilization of high plasticity clay with lime and gypsum (Ankara, Turkey). Bull. Eng. Geol. Environ. 2016, 75, 735-744. [CrossRef] 